\title{
The symbiotic relationship between Caenorhabditis elegans and members of its microbiome contributes to worm fitness and lifespan extension
}

\author{
Orçun Haçariz ${ }^{1}$, Charles Viau ${ }^{1}$, Farial Karimian ${ }^{1}$ and Jianguo Xia ${ }^{1,2^{*}}$
}

\begin{abstract}
Background: A healthy microbiome influences host physiology through a mutualistic relationship, which can be important for the host to cope with cellular stress by promoting fitness and survival. The mammalian microbiome is highly complex and attributing host phenotypes to a specific member of the microbiome can be difficult. The model organism Caenorhabditis elegans and its native microbiome, discovered recently, can serve as a more tractable, experimental model system to study host-microbiome interactions. In this study, we investigated whether certain members of $C$. elegans native microbiome would offer a benefit to their host and putative molecular mechanisms using a combination of phenotype screening, omics profiling and functional validation.

Results: A total of 16 members of C. elegans microbiome were screened under chemically-induced toxicity. Worms grown with Chryseobacterium sp. CHNTR56 MYb120 or Comamonas sp. 12022 MYb131, were most resistant to oxidative chemical stress ( $\mathrm{SiO}_{2}$ nanoparticles and juglone), as measured by progeny output. Further investigation showed that Chryseobacterium sp. CHNTR56 positively influenced the worm's lifespan, whereas the combination of both isolates had a synergistic effect. RNAseq analysis of young adult worms, grown with either isolate, revealed the enrichment of cellular detoxification mechanisms (glutathione metabolism, drug metabolism and metabolism of xenobiotics) and signaling pathways (TGF-beta and Wnt signaling pathways). Upregulation of cysteine synthases (cys/ genes) in the worms, associated with glutathione metabolism, was also observed. Nanopore sequencing uncovered that the genomes of the two isolates have evolved to favor the specific route of the de novo synthesis pathway of vitamin B6 (cofactor of cysl enzymes) through serC or pdxA2 homologs. Finally, co-culture with vitamin B6 extended worm lifespan.
\end{abstract}

Conclusions: In summary, our study indicates that certain colonizing members of C. elegans have genomic diversity in vitamin B6 synthesis and promote host fitness and lifespan extension. The regulation of host cellular detoxification genes (i.e. gst) along with cysl genes at the transcriptome level and the bacterium-specific vitamin B6 synthesis mechanism at the genome level are in an agreement with enhanced host glutathione-based cellular detoxification due to this interspecies relationship. C. elegans is therefore a promising alternative model to study host-microbiome interactions in host fitness and lifespan.

\footnotetext{
* Correspondence: jeff.xia@mcgill.ca

${ }^{1}$ Institute of Parasitology, McGill University, Montreal, Quebec, Canada

2Department of Animal Science, McGill University, Montreal, Quebec, Canada
}

(c) The Author(s). 2021 Open Access This article is licensed under a Creative Commons Attribution 4.0 International License, which permits use, sharing, adaptation, distribution and reproduction in any medium or format, as long as you give appropriate credit to the original author(s) and the source, provide a link to the Creative Commons licence, and indicate if changes were made. The images or other third party material in this article are included in the article's Creative Commons licence, unless indicated otherwise in a credit line to the material. If material is not included in the article's Creative Commons licence and your intended use is not permitted by statutory regulation or exceeds the permitted use, you will need to obtain permission directly from the copyright holder. To view a copy of this licence, visit http://creativecommons.org/licenses/by/4.0/ The Creative Commons Public Domain Dedication waiver (http://creativecommons.org/publicdomain/zero/1.0/) applies to the data made available in this article, unless otherwise stated in a credit line to the data. 
Keywords: RNAseq, Nanopore sequencing, C. elegans, Host-microbiome interaction, Cellular detoxification, Signaling pathways, Lifespan

\section{Background}

Through evolution, symbiotic microorganisms are found to be in a wide variety of relationships with their host, which can be categorised as parasitic, commensal or mutualistic. The normal mammalian microbiome (defined as the totality of microbe species found in or on the host) has evolved to be mainly mutualistic, with significant effects on host development, immunity and metabolism [14]. Interruptions in the balance of such host-microbiome relationships, known as dysbiosis, can lead to diseases [5]. Understanding such complex interactions is critical to the development of rational microbial therapies. However, elucidating causal relationships between members of the microbiome and mammalian hosts is difficult due to diverse factors such as host genetics and environmental variability [6]. Mice are commonly used to study hostmicrobiome interactions based on their similarities to humans in terms of genetics, immune system, as well as the anatomy and physiology of the digestive tract [7]. However, the mouse model has limited throughput and complex genetic interactions with its microbiome [8]. In addition, the cost associated with microbiome studies on mammals can be exorbitant. Simplified, less costly alternative models are often desirable [7].

The use of alternative models to study host-microbiome interactions has gained traction in recent years. For example, Drosophila melanogaster, the fruit fly, with its simple microbiome and its tractability and high-throughput capability, is a well-established model to study the effects of the microbiome on the host, including mate selection [9-11]. Another model organism that has become attractive in studying the microbiome is the nematode bacterivore Caenorhabditis elegans. The bacteria species comprising the native microbiome of this model organism were characterized by several research groups in 2016 [12-14].

The native microbiome of $C$. elegans mainly consists of four bacteria phyla including Bacteroidetes, Actinobacteria, Firmicutes and Proteobacteria [12, 15]. These four phyla are also present in human gut microbiome [6]. Since then, several studies have highlighted the impact of the C. elegans microbiome on the physiology of the worm. For example, Cassidy et al. [16] investigated the effects of Ochrobactrum isolates on C. elegans and demonstrated that the levels of the worms' protein expression (lipase, proteases and glutathione metabolism) were increased and the levels of the worm's proteins related to both degradation and biosynthesis of amino acids were decreased. Yang et al. [17] showed that Ochrobactrum isolates modulated $C$. elegans physiology through metabolism of specific amino acids, fatty acids, and also folate biosynthesis. However, the biological influence of the vast majority of the native microbiome members of C. elegans has not yet been investigated.

As C. elegans is a bacterivore, phenotypes of worms grown with a single bacterial isolate (i.e. monoxenic cultures) can be screened and studied in terms of fitness in response to chemical perturbations. A chemical perturbation usually causes cellular oxidative stress, which has effects on host fitness, such as reproduction (progeny output) [18-21]. To establish this in experimental studies, various chemicals including $\mathrm{SiO}_{2}$ nanoparticles and juglone, can be used. $\mathrm{SiO}_{2}$ nanoparticles and juglone, are classified as metal oxide nanoparticles and a naphthoquinone, respectively $[22,23])$. Both $\mathrm{SiO}_{2}$ nanoparticles and juglone cause oxidative stress by generating reactive oxygen species (ROS) which can react with nucleic acids, proteins and lipids, and damage the cell $[23,24]$.

The native bacteria, which are fed to the worm, can colonize the worm's inner surfaces (the most likely sites being the pharynx and intestine). Colonization by the members of the microbiome in C. elegans can be confirmed by Fluorescence In Situ Hybridization (FISH) or by destruction of antibiotic-treated C. elegans and visual inspection of colonies after plating the homogenate on plates $[12,25]$. After colonization, bacteria can potentially modulate of the effect of chemical perturbations by interacting with the host.

We hypothesized that microbiome members of C. elegans would have a beneficial effect on the worm under oxidative stress conditions by using $\mathrm{SiO}_{2}$ and juglone, of which toxicity is known to be mediated through cellular oxidative stress $[19,20]$. We first evaluated the 16 known members of the C. elegans native microbiome in $\mathrm{SiO}_{2}$ nanoparticle toxicity screening, by testing the young adult worms' response in dealing with toxicity as measured by progeny output. Based on the results, we selected two bacterial isolates (Chryseobacterium sp. CHNTR56 MYb120 and Comamonas sp. 12022 MYb131 and investigated their effects on the lifespan of the host worms. To gain insights of the potential molecular mechanisms, we further performed a comprehensive RNAseq on the worm hosts and whole genome sequencing on the bacterial isolates. Finally, we validated the effects of the constant supply of an essential vitamin, vitamin B6, hypothesized to be important in the relationship between $C$. elegans and its colonizing native bacterial isolates, on worm lifespan, as suggested by the omics data. 


\section{Results}

Some native bacterial isolates enhance the Worm's capacity in dealing with toxicity based on increased progeny production

As microbiome members are implicated in host fitness, we tested their effects on $C$. elegans reproduction (progeny output) under stress conditions by feeding the worm the corresponding bacterial diet. Initially, L1 $C$. elegans larvae were incubated with each of 16 native bacterial isolates (Additional file 1) or E. coli OP50 on NGM plates. Several bacteria (Arthrobacter aurescens MYb27, Microbacterium oxydans MYb45, Rhodococcus erythropolis PR4 MYb53 and Bacillus sp. SG20 MYb56) could not be included in the analysis as the larva number and/or size of the worms grown with these bacteria was not sufficient. L4-young adult C. elegans were then screened for progeny output in a liquid-based assay in the presence of $\mathrm{SiO}_{2}$ nanoparticles and the microbiome members. The isolates with better maintained progeny output ( $>50 \%$ of the control value) (Fig. 1a) were further tested with $\mathrm{SiO}_{2}$ and juglone, in triplicate. Worms grown with Chryseobacterium sp. CHNTR56 MYb120 or Comamonas sp. 12022 MYb131 showed significantly higher ratio in progeny output under $\mathrm{SiO}_{2}$ or juglone toxicity, compared to the worms grown with $E$. coli OP50 $(P<0.0001)$ (Fig. 1b).

Total progeny production of the worms grown with $E$. coli OP50 was higher compared to that of the worms grown with the native bacterial isolates, and the progeny production rate between the worms grown with these isolates was mainly similar in the control wells (in the absence of experimentally induced toxicity). Worms grown with E. coli OP50 as well as with many of the other bacterial isolates did not show the beneficial effect against toxicity as worms grown with Chryseobacterium sp. CHNTR56 MYb120 or Comamonas sp. 12022 MYb131 (Fig. 1a). In terms of ratio of progeny production, Chryseobacterium and Comamonas fed worms far exceeded the ratio for E. coli OP50 fed worms (Fig. 1a, b). Overall, these findings suggested that these members of the worm's microbiome, when fed to the worm, provided a beneficial effect against toxic compounds, observed by the improvement of host fitness (i.e. reproduction) under stress conditions.

\section{The native bacterial isolates colonize the worm host and extend lifespan}

The colonization assay supported that microbiome members interact differently with $C$. elegans compared to $E$. coli OP50. According to recent reports, native microbiome members colonize $C$. elegans more efficiently than non-native bacteria, such as $E$. coli OP50 $[12,14,17]$. By plating on TSB plates with no antibiotics, we determined that the tested native bacteria including
Chryseobacterium sp. CHNTR56 MYb120 or Comamonas sp. 12022 MYb131, were still culturable from the worms with no food after a 24-h period (incubated on NGM plates containing effective antibiotics against the native bacterial isolates), indicating that these bacteria have colonized the worm host. This assay was further supported by the absence or negligible number of colonies for the non-native and non-colonizing bacterium, E. coli OP50 (Additional file 2, Fig. S1). In Additional file 2, Fig. S1, the number of E. coli OP50 colonies (as seen by the colony forming units) recovered is much lesser compared to the number of native bacteria colonies recovered from the worms, indicating that these native bacteria colonize inside the worm. The most likely sites of colonization are the worm intestine and pharynx, as the worms' outside surface (i.e. cuticle) was sterilized by antibiotic treatment. The colonization assay suggested that C. elegans may respond differently to a microbiome member diet, due in part to worm colonization, compared to a standard E. coli OP50 diet.

As the colonizing Chryseobacterium sp. CHNTR56 MYb120 or Comamonas sp. 12022 MYb131 isolates had a benefit on progeny output under stressful conditions, indicating an enhanced cellular protection to toxicity, we questioned whether they could have an influence on worm lifespan. We monitored whether Chryseobacterium sp. CHNTR56 MYb120 or Comamonas sp. 12022 MYb131 when fed to C. elegans, influenced worm physiology, resulting in altered lifespan, compared to a standard E. coli OP50 diet (Fig. 2, Table 1). The median lifespan of $C$. elegans grown with $E$. coli OP50 was found to be 10 , which is close to the range reported for the lifespan of wild type N2 strain under similar conditions where worms are transferred frequently and FUDR is not used [26-29]. The observation of shorter lifespan, in comparison with experiments using FUDR (average mean lifespan can be around 14-16 days) [30, 31], was expected due to longer light exposure (as worms were transferred to fresh plates daily) that causes reduced lifespan in C. elegans [32]. In the present study, C. elegans grown with E. coli OP50 or Comamonas sp. 12022 MYb131 showed similar survival rates, however, worms grown with Chryseobacterium sp. CHNTR56 MYb120 demonstrated lifespan extension (only maximum, 25\% increase, compared to worms grown with E. coli OP50, $P=0.0122)$. More interestingly, worms grown with the combination of both native bacterial isolates had an extended overall lifespan (maximum, 41\% increase compared to $E$. coli OP50, $P<0.0001)$ and increased median lifespan (40\% increase compared to $E$. coli OP50, $P<$ 0.0001). Altogether, these data show that growth with Chryseobacterium sp. CHNTR56 MYb120 and the combination of bacterial isolates promote $C$. elegans lifespan extension. 

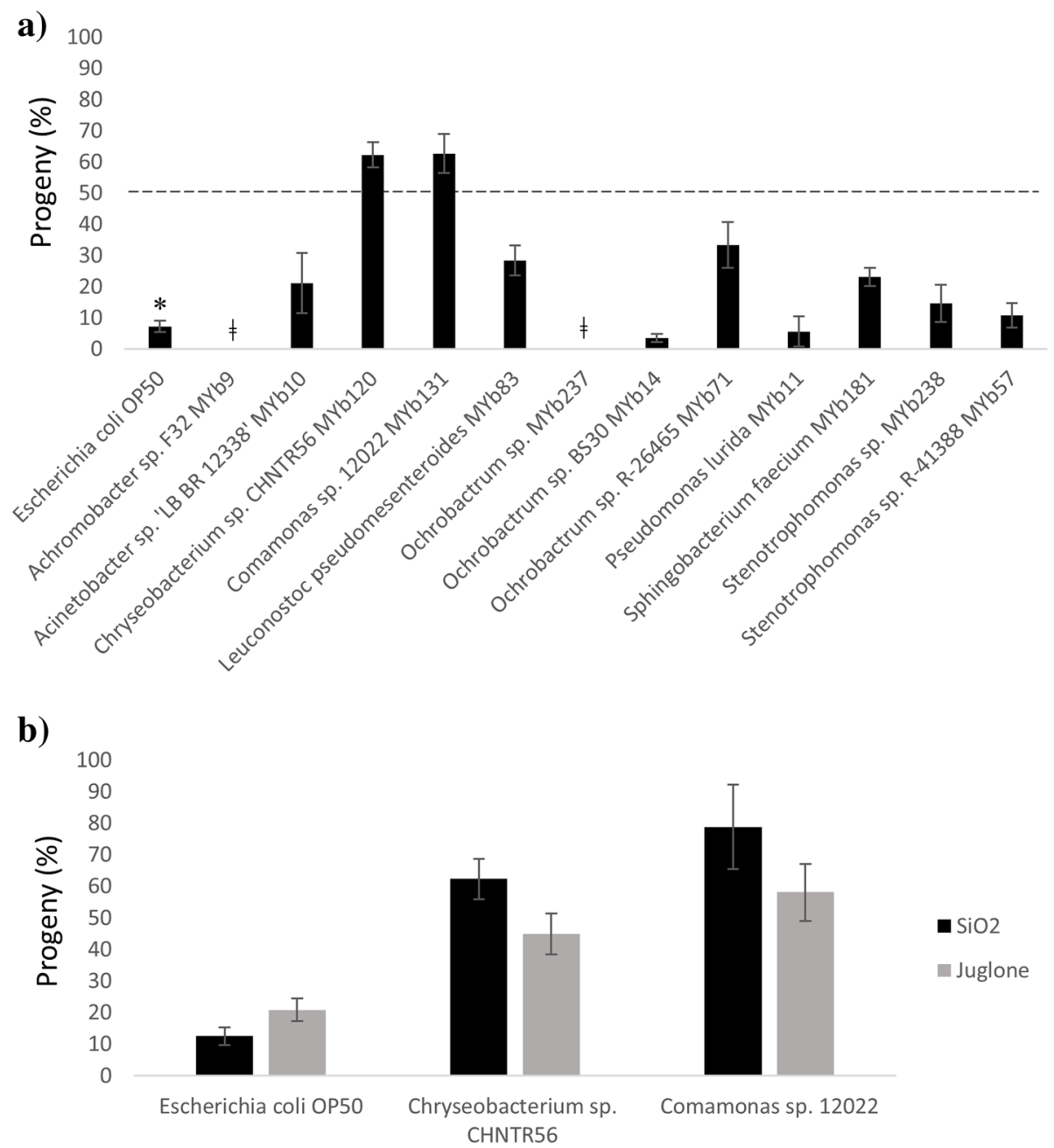

Fig. 1 Responses to toxicity as measured by progeny output. a. C. elegans grown with Chryseobacterium sp. CHNTR56 MYb120 or Comamonas sp. 12022 MYb131 provided a progeny output (\%) greater than 50\% (compared to untreated control) under $\mathrm{SiO} 2$ toxicity $\left(50 \mu \mathrm{gg} / \mathrm{ml} \mathrm{of} \mathrm{SiO}_{2}\right)$ in the initial screening. b. The progeny output for the worms grown with Chryseobacterium sp. CHNTR56 MYb120 or Comamonas sp. 12022 MYb131, compared to the worms grown with $E$. coli OP50, in the presence of $\mathrm{SiO}_{2}$ or juglone $(50 \mu \mathrm{M}) *$ : The progeny output for $E$. coli OP50 is the mean value calculated from each plate used (value for standard error of mean was negligible, 3.61\%). ‡: No progeny detectable under toxicity

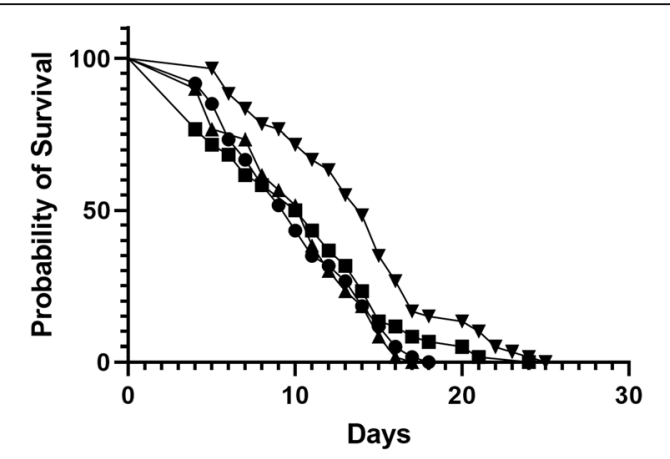

- Escherichia coli OP50

- Chryseobacterium sp.

- CHNTR56 MYb120

- Comamonas sp. 12022 MYb131

$\rightarrow$ Combination

Fig. 2 Survival of the worms grown with different bacterial isolates over time. Survival curves are shown. Growth with Chryseobacterium sp. CHNT R56 MYb120 alone extended worm maximum lifespan $(P=0.0122)$, and the combination of both native bacteria isolates (Chryseobacterium sp. CHNTR56 MYb120 and Comamonas sp. 12022 MYb131) increased worm median and maximum lifespans $(P<0.0001)$, compared to the worms grown E. coli OP50. This experiment was replicated three times and worms were kept at $21{ }^{\circ} \mathrm{C}$ 
Table 1 Lifespan of the worms grown with different native bacterial isolates

\begin{tabular}{lllllll}
\hline Bacteria isolate & $\begin{array}{l}\text { Number of live worms } \\
\text { per replicate }\end{array}$ & $\begin{array}{l}\text { Number of dead worms } \\
\text { per replicate }\end{array}$ & $\begin{array}{l}\text { Median } \\
\text { survival } \\
\text { (days) }\end{array}$ & $\begin{array}{l}\text { Maximum } \\
\text { survival } \\
\text { (days) }\end{array}$ & $\begin{array}{l}\text { Median } \\
\text { lifespan } \\
\text { (P value) }\end{array}$ & $\begin{array}{l}\text { Maximum lifespan } \\
\text { (P value) }\end{array}$ \\
\hline $\begin{array}{l}\text { Escherichia coli OP50 } \\
\begin{array}{l}\text { Chryseobacterium sp. CHNT } \\
\text { R56 MYb120 }\end{array}\end{array} 20$ & 20 & 10 & 16 & - & - \\
$\begin{array}{l}\text { Comamonas sp. 12022 } \\
\text { MYb131 }\end{array}$ & 20 & 20 & 10.5 & 20 & 0.3201 & 0.0122 \\
Combination & 20 & 20 & 11 & 16 & 0.8128 & 0.5634 \\
\end{tabular}

Lifespan values and related statistics for the worms grown with the native bacterial isolates of interest and E. coli OP50 are shown. Maximum lifespan of the worms grown with Chryseobacterium sp. CHNTR56 MYb120 alone and median and maximum lifespans of the worms grown with the combination of both native bacterial isolates were increased, compared to the worms grown $E$. coli OP50 $(P=0.0122$ and $P<0.0001$, respectively). No worms were censored

The native bacterial isolates upregulate detoxification genes in C. elegans

We further investigated the C. elegans transcriptomic response when the worm is grown with members of its microbiome as compared to growth with non-colonizing bacteria, such as E. coli OP50. RNAseq analysis of C. elegans grown with Chryseobacterium sp. CHNTR56 MYb120, Comamonas sp. 12022 MYb131 or E. coli OP50 yielded around 20 million reads for each sample ( $n=3$, for each phenotype). Approximately 18,000 features were identified and $94 \%$ of these features were assigned to the worm's genes. The similarity of the samples based on their gene expression patterns was inspected by principal component analysis (PCA), which shows a clear separation of the various samples based on the fed diet (Fig. 3). Statistically significant differentially expressed genes (DEGs; defined by edgeR, FDR $<0.05$ ) of the worms grown with the native bacteria (Chryseobacterium sp. CHNTR56 MYb120 or Comamonas sp. 12022 MYb131) versus E. coli OP50 are shown in
Additional file 3. The number of DEGs (with fold change greater than 1) for the worms grown with Chryseobacterium sp. CHNTR56 MYb120 or Comamonas sp. 12022 MYb131, compared to E. coli OP50, were 6109 and 3049 , respectively, indicating that $C$. elegans is more responsive to Chryseobacterium sp. CHNTR56 MYb120. The number of C. elegans DEGs induced by each native bacterial isolate is shown in a Venn diagram (Additional file 4, Fig. S2).

Transcriptome analysis of worms grown with Chryseobacterium sp. CHNTR56 MYb120 or Comamonas sp. 12022 MYb131 showed enrichment of various biological processes based on gene ontology (GO) annotation (Table 2) and pathways according to KEGG database (Table 3). Most notably, cellular detoxification mechanisms were enriched, which include glutathione metabolism, drug metabolism and metabolism of xenobiotics by cytochrome P450 enzymes in both Chryseobacterium sp. CHNTR56 MYb120 and Comamonas sp. 12022 MYb131 fed groups, suggesting that the bacterial isolates

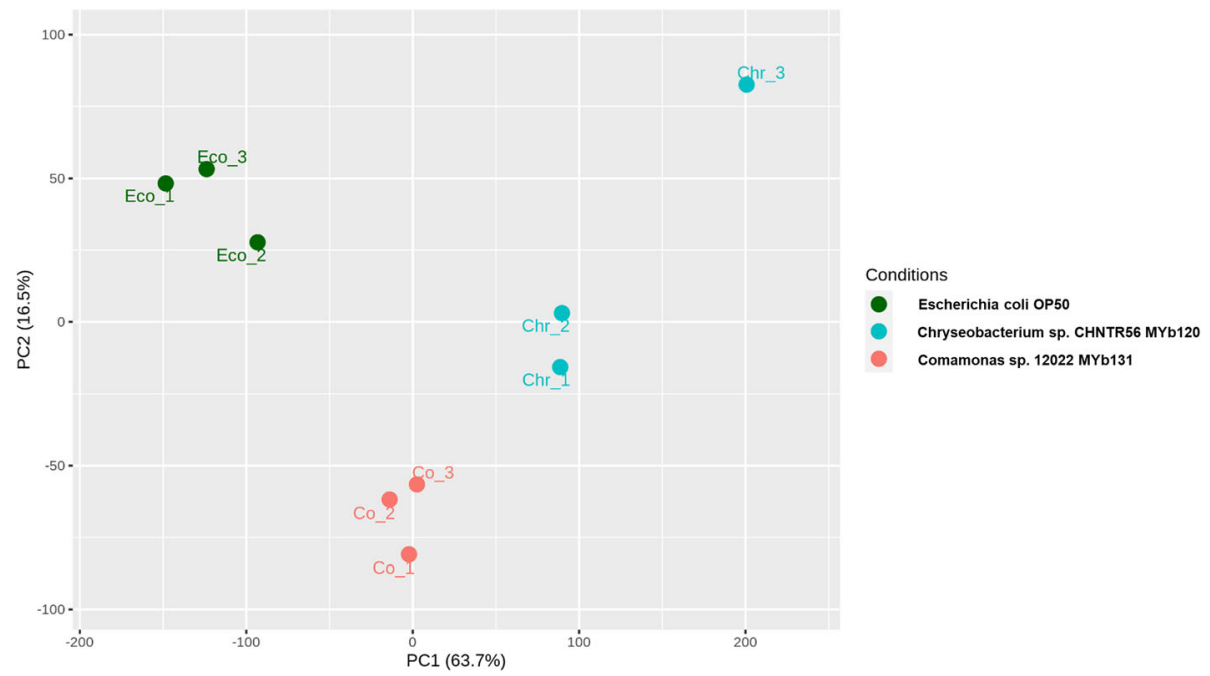

Fig. 3 Principal component analysis (PCA). PCA demonstrates the similarity of the samples based on their gene expression patterns in a two dimensional space. These samples include the worms grown with E. coli OP50, Chryseobacterium sp. CHNTR56 MYb120 or Comamonas sp. 12022 MYb131 
Table 2 Top 20 enriched biological processes. Gene enrichment was performed using over-representation analysis with NetworkAnalyst [33]

\begin{tabular}{|c|c|c|c|c|c|c|c|c|}
\hline Pathways & $\begin{array}{l}\text { Worms grown with } \\
\text { Chryseobacterium sp. CHNTR56 } \\
\text { MYb120 }\end{array}$ & Rank & $\begin{array}{l}\text { Hits/ } \\
\text { Total }\end{array}$ & P.Value & $\begin{array}{l}\text { Worms grown with Comamonas } \\
\text { sp. } 12022 \text { MYb131 }\end{array}$ & Rank & $\begin{array}{l}\text { Hits/ } \\
\text { Total }\end{array}$ & P.Value \\
\hline Behaviour & Locomotory behavior & 10 & $\begin{array}{l}16 / \\
40\end{array}$ & 0.0077 & - & - & - & - \\
\hline Biological phase & M phase of mitotic cell cycle & 13 & $4 / 5$ & 0.00964 & - & - & - & - \\
\hline Biological regulation & $\begin{array}{l}\text { Regulation of sequence specific DNA } \\
\text { binding transcription factor activity }\end{array}$ & 9 & $\begin{array}{l}10 / \\
20\end{array}$ & 0.00536 & $\begin{array}{l}\text { Regulation of sequence specific } \\
\text { DNA binding transcription factor } \\
\text { activity }\end{array}$ & 18 & $7 / 20$ & 0.00561 \\
\hline \multirow{3}{*}{$\begin{array}{l}\text { Cellular component } \\
\text { organization or } \\
\text { biogenesis }\end{array}$} & Protein oligomerization & 2 & $\begin{array}{l}20 / \\
39\end{array}$ & $\begin{array}{l}5.51 \mathrm{E}- \\
05\end{array}$ & Protein oligomerization & 19 & $\begin{array}{l}10 / \\
39\end{array}$ & 0.0118 \\
\hline & Protein homooligomerization & 3 & $\begin{array}{l}19 / \\
37\end{array}$ & $\begin{array}{l}8.26 \mathrm{E}- \\
05\end{array}$ & - & & - & - \\
\hline & Chromosome condensation & 7 & $7 / 11$ & 0.0035 & - & & - & - \\
\hline \multirow[t]{4}{*}{ Cellular process } & Dephosphorylation & 4 & $\begin{array}{l}48 / \\
140\end{array}$ & 0.00052 & Dephosphorylation & 2 & $\begin{array}{l}46 / \\
140\end{array}$ & 1.7E-11 \\
\hline & Protein dephosphorylation & 1 & $\begin{array}{l}48 / \\
121\end{array}$ & 7.6E-06 & Protein dephosphorylation & 1 & $\begin{array}{l}46 / \\
121\end{array}$ & $4.1 \mathrm{E}-14$ \\
\hline & $\begin{array}{l}\text { Negative regulation of nucleobase } \\
\text { containing compound metabolic } \\
\text { process }\end{array}$ & 14 & $\begin{array}{l}25 / \\
73\end{array}$ & 0.0108 & Phosphorylation & 9 & $\begin{array}{l}86 / \\
504\end{array}$ & 0.00013 \\
\hline & Neuropeptide signaling pathway & 17 & $9 / 19$ & 0.0126 & Protein phosphorylation & 5 & $\begin{array}{l}86 / \\
470\end{array}$ & 8.7E-06 \\
\hline \multirow[t]{9}{*}{ Developmental process } & - & - & - & - & Nervous system development & 16 & $\begin{array}{l}50 / \\
286\end{array}$ & 0.00193 \\
\hline & - & - & - & - & Neurogenesis & 15 & $\begin{array}{l}47 / \\
262\end{array}$ & 0.00152 \\
\hline & - & - & - & - & Generation of neurons & 14 & $\begin{array}{l}47 / \\
260\end{array}$ & 0.00129 \\
\hline & - & - & - & - & Neuron differentiation & 12 & $\begin{array}{l}44 / \\
230\end{array}$ & 0.00055 \\
\hline & - & - & - & - & Neuron development & 11 & $\begin{array}{l}41 / \\
207\end{array}$ & 0.0004 \\
\hline & - & - & - & - & Neuron projection development & 13 & $\begin{array}{l}37 / \\
192\end{array}$ & 0.00128 \\
\hline & - & - & - & - & Epithelial cell differentiation & 6 & $\begin{array}{l}13 / \\
30\end{array}$ & $1.2 \mathrm{E}-05$ \\
\hline & - & - & - & - & Epidermis development & 20 & $7 / 23$ & 0.013 \\
\hline & - & - & - & - & Mesoderm development & 17 & $\begin{array}{l}10 / \\
31\end{array}$ & 0.00195 \\
\hline \multirow[t]{5}{*}{ Metabolic process } & DNA replication & 20 & $\begin{array}{l}21 / \\
62\end{array}$ & 0.021 & - & & & \\
\hline & DNA replication initiation & 6 & $5 / 6$ & 0.00252 & Macromolecule modification & 4 & $\begin{array}{l}147 / \\
896\end{array}$ & $3.9 \mathrm{E}-06$ \\
\hline & $\begin{array}{l}\text { Negative regulation of RNA metabolic } \\
\text { process }\end{array}$ & 11 & $\begin{array}{l}22 / \\
61\end{array}$ & 0.00838 & Protein modification process & 3 & $\begin{array}{l}146 / \\
848\end{array}$ & $2.3 \mathrm{E}-07$ \\
\hline & $\begin{array}{l}\text { Negative regulation of transcription, } \\
\text { DNA dependent }\end{array}$ & 12 & $\begin{array}{l}22 / \\
61\end{array}$ & 0.00838 & - & & - & - \\
\hline & $\begin{array}{l}\text { Negative regulation of transcription } \\
\text { from RNA polymerase II promoter }\end{array}$ & 18 & $\begin{array}{l}16 / \\
43\end{array}$ & 0.0167 & - & & - & - \\
\hline \multirow[t]{2}{*}{$\begin{array}{l}\text { Multicellular } \\
\text { organismal process }\end{array}$} & $\begin{array}{l}\text { Detection of stimulus involved in } \\
\text { sensory perception }\end{array}$ & 8 & $6 / 9$ & 0.00509 & - & & - & - \\
\hline & Regulation of muscle contraction & 19 & $9 / 20$ & 0.0185 & - & & - & - \\
\hline
\end{tabular}


Table 2 Top 20 enriched biological processes. Gene enrichment was performed using over-representation analysis with NetworkAnalyst [33] (Continued)

\begin{tabular}{|c|c|c|c|c|c|c|c|c|}
\hline Pathways & $\begin{array}{l}\text { Worms grown with } \\
\text { Chryseobacterium sp. CHNTR56 } \\
\text { MYb120 }\end{array}$ & Rank & $\begin{array}{l}\text { Hits/ } \\
\text { Total }\end{array}$ & P.Value & $\begin{array}{l}\text { Worms grown with Comamonas } \\
\text { sp. } 12022 \text { MYb131 }\end{array}$ & Rank & $\begin{array}{l}\text { Hits/ } \\
\text { Total }\end{array}$ & P.Value \\
\hline \multirow[t]{2}{*}{ Multi-organism process } & Spermatid differentiation & 16 & $7 / 13$ & 0.012 & Spermatid differentiation & 8 & $8 / 13$ & $2.5 \mathrm{E}-05$ \\
\hline & Spermatid development & 15 & $7 / 13$ & 0.012 & Spermatid development & 7 & $8 / 13$ & $2.5 \mathrm{E}-05$ \\
\hline Response to stimulus & Detection of stimulus & 5 & $8 / 13$ & 0.00238 & Response to wounding & 10 & $7 / 12$ & 0.00013 \\
\hline
\end{tabular}

Enriched biological processes ranked by P-value and categorised based on an online resource (Mouse Genome Informatics, https://www.informatics.jax.org/) are shown

Table 3 Top 20 enriched biological pathways

\begin{tabular}{|c|c|c|c|c|c|c|c|c|c|c|c|}
\hline \multicolumn{6}{|c|}{ Worms grown with Chryseobacterium sp. CHNTR56 MYb120 } & \multicolumn{6}{|c|}{ Worms grown with Comamonas sp. 12022 MYb131 } \\
\hline Pathway & Total & Expected & Hits & P.Value & FDR & Pathway & Total & Expected & Hits & P.Value & FDR \\
\hline DNA replication & 33 & 4.83 & 17 & $5.32 \mathrm{E}-07$ & $\begin{array}{l}6.64 \mathrm{E}- \\
05\end{array}$ & Circadian rhythm - mammal & 23 & 1.43 & 10 & $3.49 \mathrm{E}-07$ & 4.36E-05 \\
\hline TGF-beta signaling pathway & 33 & 4.83 & 14 & 9.06E-05 & 0.00383 & TGF-beta signaling pathway & 33 & 2.05 & 11 & 2.09E-06 & 0.000131 \\
\hline Glutathione metabolism* & 38 & 5.56 & 15 & 0.000136 & 0.00383 & $\begin{array}{l}\text { Drug metabolism - } \\
\text { cytochrome P450* }\end{array}$ & 32 & 1.99 & 10 & $1.21 \mathrm{E}-05$ & 0.000505 \\
\hline Circadian rhythm - mammal & 23 & 3.37 & 11 & 0.000144 & 0.00383 & $\begin{array}{l}\text { Metabolism of xenobiotics } \\
\text { by cytochrome P450* }\end{array}$ & 29 & 1.81 & 9 & $3.63 \mathrm{E}-05$ & 0.00113 \\
\hline Wnt signaling pathway & 64 & 9.37 & 21 & 0.000153 & 0.00383 & Wnt signaling pathway & 64 & 3.98 & 13 & $9.65 \mathrm{E}-05$ & 0.00241 \\
\hline Fatty acid metabolism & 56 & 8.2 & 17 & 0.00177 & 0.0357 & Peroxisome & 64 & 3.98 & 12 & 0.000403 & 0.00731 \\
\hline $\begin{array}{l}\text { Taurine and hypotaurine } \\
\text { metabolism }\end{array}$ & 5 & 0.732 & 4 & 0.002 & 0.0357 & $\begin{array}{l}\text { Cysteine and methionine } \\
\text { metabolism }\end{array}$ & 31 & 1.93 & 8 & 0.00042 & 0.00731 \\
\hline $\begin{array}{l}\text { Drug metabolism - } \\
\text { cytochrome P450* }\end{array}$ & 32 & 4.69 & 11 & 0.004 & 0.0625 & Fatty acid metabolism & 56 & 3.49 & 11 & 0.000468 & 0.00731 \\
\hline Calcium signaling pathway & 42 & 6.15 & 13 & 0.00508 & 0.0706 & Glutathione metabolism* & 38 & 2.37 & 8 & 0.0018 & 0.0225 \\
\hline $\begin{array}{l}\text { Metabolism of xenobiotics } \\
\text { by cytochrome P450* }\end{array}$ & 29 & 4.25 & 10 & 0.00587 & 0.0734 & $\begin{array}{l}\text { Taurine and hypotaurine } \\
\text { metabolism }\end{array}$ & 5 & 0.311 & 3 & 0.00215 & 0.0225 \\
\hline Mismatch repair & 18 & 2.64 & 7 & 0.01 & 0.114 & $\begin{array}{l}\text { Arginine and proline } \\
\text { metabolism }\end{array}$ & 39 & 2.43 & 8 & 0.00215 & 0.0225 \\
\hline $\begin{array}{l}\text { Biosynthesis of unsaturated } \\
\text { fatty acids }\end{array}$ & 16 & 2.34 & 6 & 0.0206 & 0.215 & $\begin{array}{l}\text { Biosynthesis of unsaturated } \\
\text { fatty acids }\end{array}$ & 16 & 0.996 & 5 & 0.00216 & 0.0225 \\
\hline $\begin{array}{l}\text { Fatty acid elongation in } \\
\text { mitochondria }\end{array}$ & 13 & 1.9 & 5 & 0.0306 & 0.285 & $\begin{array}{l}\text { Limonene and pinene } \\
\text { degradation }\end{array}$ & 17 & 1.06 & 5 & 0.00291 & 0.0279 \\
\hline Pyrimidine metabolism & 68 & 9.96 & 16 & 0.0319 & 0.285 & Phenylalanine metabolism & 18 & 1.12 & 5 & 0.00383 & 0.0342 \\
\hline Phenylalanine metabolism & 18 & 2.64 & 6 & 0.037 & 0.307 & $\begin{array}{l}\text { Ubiquitin mediated } \\
\text { proteolysis }\end{array}$ & 84 & 5.23 & 12 & 0.00474 & 0.0395 \\
\hline $\begin{array}{l}\text { Neuroactive ligand-receptor } \\
\text { interaction }\end{array}$ & 23 & 3.37 & 7 & 0.0404 & 0.307 & Nitrogen metabolism & 21 & 1.31 & 5 & 0.00781 & 0.0611 \\
\hline $\begin{array}{l}\text { Cyanoamino acid } \\
\text { metabolism }\end{array}$ & 6 & 0.879 & 3 & 0.0442 & 0.307 & Tyrosine metabolism & 22 & 1.37 & 5 & 0.00962 & 0.0707 \\
\hline Sulfur metabolism & 6 & 0.879 & 3 & 0.0442 & 0.307 & ECM-receptor interaction & 8 & 0.498 & 3 & 0.0105 & 0.0727 \\
\hline $\begin{array}{l}\text { Progesterone-mediated } \\
\text { oocyte maturation }\end{array}$ & 39 & 5.71 & 10 & 0.0487 & 0.315 & Lysosome & 76 & 4.73 & 10 & 0.0172 & 0.113 \\
\hline- & & & & & & $\begin{array}{l}\text { alpha-Linolenic acid } \\
\text { metabolism }\end{array}$ & 11 & 0.685 & 3 & 0.0269 & 0.168 \\
\hline
\end{tabular}


regulate these biological pathways in the worm. Heatmap analysis revealed DEGs for cellular detoxification mechanisms in worms grown with each bacterial isolate of interest (Fig. 4). These included genes encoding for glutathione S-transferases (GSTs) and other enzymes such as alcohol dehydrogenases (SODH-1 and SODH-2) associated with the translocation of DAF-16, a regulator of longevity, into the nucleus [34-39]. For the C. elegans enriched pathways in cellular detoxification (Fig. 4), some genes showed homology with human genes and relation to aging. These included genes that encode protein RNR-2 [rnr-2, associated with anti-longevity in $C$. elegans by Human Ageing Genomic Resources (HAGR) [40]; human ortholog: RRM2B, reported by Ortholist2 [41], which was downregulated in Chryseobacterium sp. CHNTR56 MYb120 fed group, dimethylaniline monooxygenase [N-oxide-forming] [fmo-2, associated with prolongevity in $C$. elegans by HAGR; human ortholog: FMO3, reported by Ortholist2], which was upregulated in the Comamonas sp.12022 fed group, and glutathione S-transferase-5 (gst-5, associated with pro-longevity in $C$. elegans; human ortholog: GSTA4, based on Ortholist2), which was upregulated in both groups.
The cytochrome P450 family genes (cyp) were also upregulated in the worms grown with Chryseobacterium sp. CHNTR56 MYb120 (17 out of 23) or Comamonas sp. 12022 MYb131 (27 out of 28) (Additional file 5, Fig. S3), which suggests a link between the regulation of CYPs and GSTs. The expression of cyp genes along with gst genes, is known to be upregulated to reduce toxicity of endogenous and exogenous compounds [42, 43]. In this case, the native bacterial isolates may promote a low level of toxicity to trigger the expression of these enzymes. These genes are probably co-regulated in the worm as GST action follows CYP modification of substrates [44]. Furthermore, a reference gene of oxidative stress, hsp-16.2 [19], was consequently downregulated, suggesting suppression of oxidative stress, in the worms grown with each bacterial isolate.

The observed enrichment in cellular detoxification was reversely accompanied with the enrichment of TGF-beta and Wnt signaling pathways, involved in many aspects from body growth, innate immunity to longevity in $C$. elegans [45] (Fig. 5). This reverse relationship (upregulation of cellular detoxification genes but downregulation of the signaling-related genes) reflected the findings
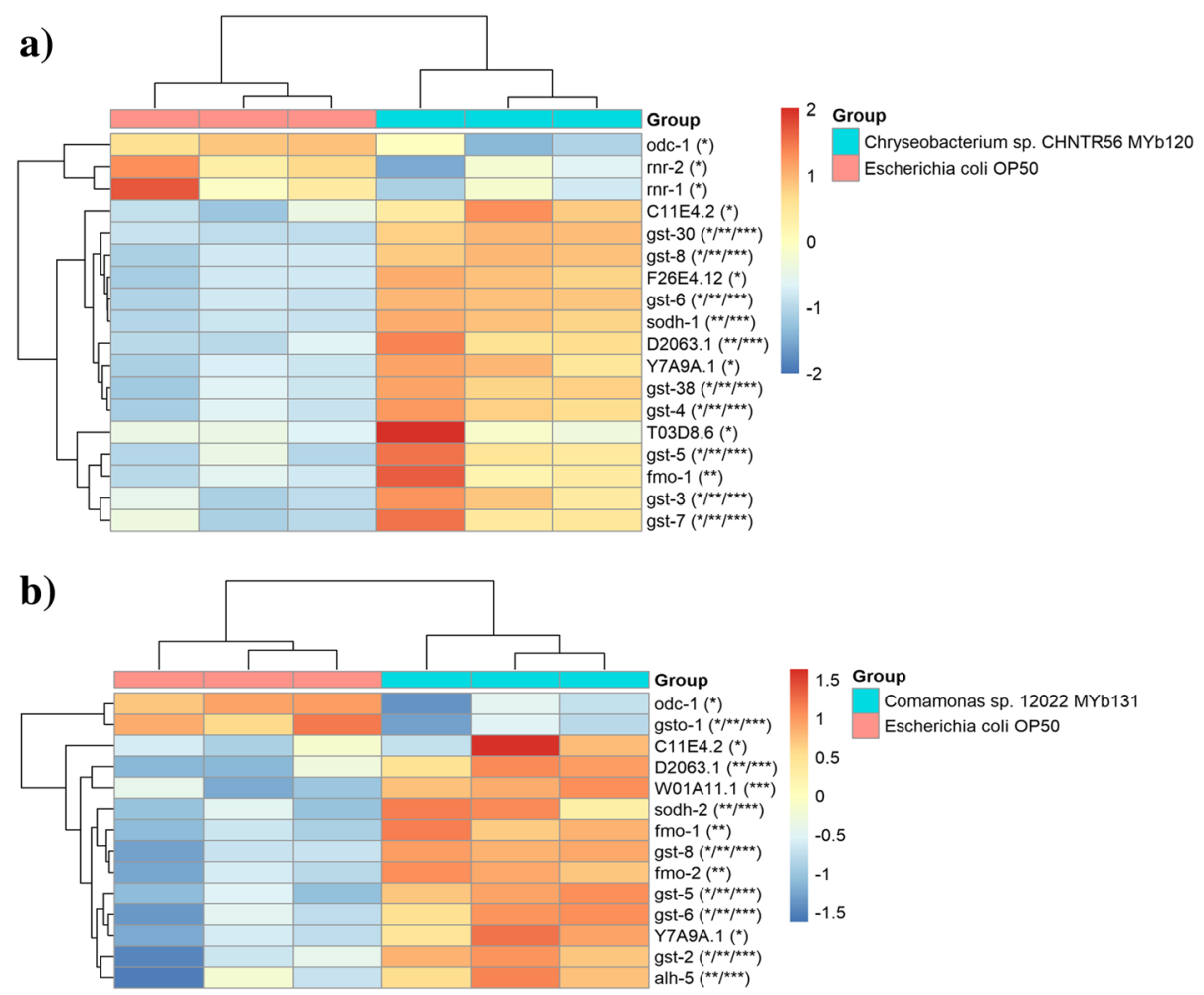

Fig. 4 Heatmap for the genes involved in the enriched cellular detoxification related pathways. DEGs were defined by edgeR with FDR $<0.05$. Cellular detoxification related enriched genes are shown for worms grown with a. Chryseobacterium sp. CHNTR56 MYb120 or b. Comamonas sp. 12022 MYb131. Cellular detoxification related genes were mainly upregulated GSTs. *: Glutathione metabolism (KEGG entry: cel00480). **: Drug metabolism - cytochrome P450 (KEGG entry: cel00982). **: Metabolism of xenobiotics by cytochrome P450 (KEGG entry: cel00980) 

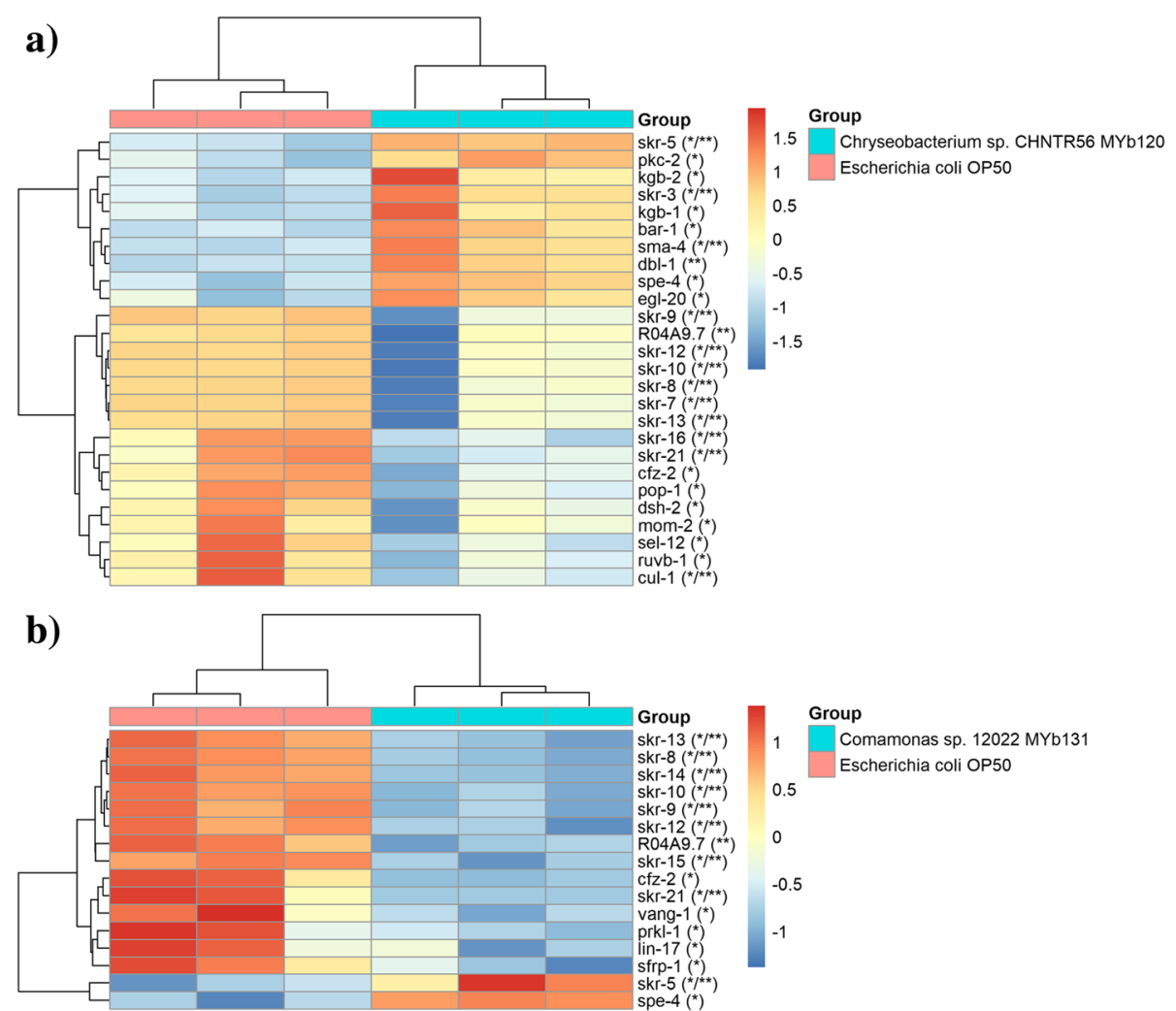

Fig. 5 Heatmap for the genes involved in the enriched signaling pathways. DEGs were defined by edgeR with FDR $<0.05$. Genes involved in TGFbeta and Wnt signaling were mainly downregulated in the worms grown with both native bacteria, a. Chryseobacterium sp. CHNTR56 MYb120 or b. Comamonas sp. 12022 MYb131, in comparison with the worms grown with E. coli OP50. *: Wnt signaling. **:TGF-beta signaling

reported in long-lived mutants (grown with E. coli OP50) [46], citing the effect of the microbiome members on worm longevity. The signaling-related genes were mainly downregulated in both pathways for the worms grown with Chryseobacterium sp. CHNTR56 MYb120 or Comamonas sp.12022. The $s k r$ genes were mostly downregulated, except $s k r-3$ and $s k r-5$, in the Chryseobacterium sp. CHNTR56 MYb120 group. The Skp1 related (ubiquitin ligase complex component) gene, $s k r-5$, having a human ortholog (SKP1; Ortholist2), is associated with anti-longevity in C. elegans (HAGR) yet the regulation of $s k r-5$ is indeed conditional [47]. Additionally, beta-catenin/armadillo-related protein 1 , having a human ortholog (CTNNB1; Ortholist2), is associated with Wnt signaling and pro-longevity in C. elegans (HAGR), was upregulated in the Chryseobacterium sp. CHNTR56 MYb120 group and protein vang-1, having a human ortholog (VANGL1; Ortholist2), is associated with Wnt signaling and anti-longevity in C. elegans (HAGR), was downregulated in the Comamonas sp. 12022 MYb131 group. Altogether, these data showed that the transcriptomic response to each of the microbiome members, Chryseobacterium sp. CHNTR56 MYb120 and Comamonas sp. $12022 \mathrm{MYb131}$, are different compared to a non- native bacterium, E. coli OP50. Both bacterial isolates upregulated the host $C$. elegans genes encoding GSTs, CYPs and downregulated genes in the TGF-beta and Wnt signaling pathways. These responses are suggested to be responsible for the benefit that Chryseobacterium sp. CHNTR56 MYb120 and Comamonas sp. 12022 MYb131 provide C. elegans under stress conditions and could explain the longevity-promoting effect of these bacteria.

The native bacterial isolates possess genomes containing multiple gene homologs involved in vitamin B6 synthesis The native bacterial isolates caused regulation of genes associated with synthesis of cysteine (required for glutathione metabolism); cysl-1, $-2,-4$ were upregulated by Chryseobacterium sp. CHNTR56 MYb120 and cysl-2, $3,-4$ were upregulated by Comamonas sp. 12022 MYb131. This suggests that cysteine synthesis appeared to be favored in C. elegans grown with native bacterial isolates, resulting in enhanced worm fitness and lifespan, most probably through supplementation of glutathione levels required for glutathione-mediated detoxification mechanisms (i.e., GSTs). Cysteine synthesis requires the active form of vitamin B6 [pyridoxal 5' -phosphate (PLP); 
co-factor of CYSL enzymes], based on the information from UniProt (www.uniprot.org) [48], we sought to determine whether the bacterial isolates of interest have the genetic repertoire to provide this vitamin to the worm.

To investigate the potential interdependency between host cysteine synthesis (catalyzed by CYSL enzymes) and vitamin B6 synthesis (co-factor of CYSL enzymes) by the native bacterial isolates, we analyzed the genomes of the bacterial isolates of interest by nanopore sequencing to determine whether the bacteria have genes to encode enzymes that synthesize the active form of vitamin B6. The vitamin B6 de novo and salvage pathways contain many enzymes, as observed in Table 4 . The N50 length of the obtained sequences was $\sim 8 \mathrm{~kb}$ and the assembly process produced one contig (with coverage $\geq 89 \mathrm{X}$ ) for each bacterium. Further details about the size of the assembled genomes with coverage depth, coding sequences and identified genes are shown in Additional file 6 .

Analysis of the bacterial genomes demonstrated that Chryseobacterium sp. CHNTR56 MYb120 and Comamonas sp. 12022 MYb131 genomes possess various gene homologs for the specific route of the vitamin B6 (pyridoxal 5'-phosphate) de novo synthesis pathway (D- erythrose 4-P is converted to 3-amino-1-hydroxyacetone 1-P4), with the predicted catalytic activity in protein translation [two $p d x B$ homologs and four $\operatorname{ser} C$ homologs in Chryseobacterium sp. CHNTR56 MYb120 and three $p d x A 2$ homologs in Comamonas sp. 12022 MYb131], in comparison to E. coli OP50 (Table 4). The presence of these gene homologs suggests 3-amino-1-hydroxyacetone 1-P4 combines preferentially with $\mathrm{D}$-xylulose 5-P more for vitamin B6 synthesis in these bacteria [as Dxylulose 5-P is a precursor which can be converted to other metabolites [49]]. This is further promoted in Chryseobacterium sp. CHNTR56 MYb120 based on the presence of two $p d x J$ homologs. Many genes (including serC, $p d x J, p d x B$ and $p d x A$ ) in Chryseobacterium sp. CHNTR56 MYb120 were not detected in the closely related species, Sphingobacterium faecium MYb181. Multiple $p d x A$ homologs, as detected in Comamonas sp. $12022 \mathrm{MYb} 131$, are present in the closely related species, Achromobacter sp. F32 MYb9. However, Achromobacter sp. F32 MYb9 lacks the gapA, epd and $p d x B$ genes, which could translate to significantly less influence of the vitamin B6 de novo synthesis pathway in this bacterium, compared to Comamonas sp. 12022 MYb131.

Based on these observations, we examined the effect of vitamin B6 on worm survival in vivo. Worms grown

Table 4 Genes that are involved in vitamin B6 metabolism and present in the bacteria genomes

\begin{tabular}{|c|c|c|c|c|}
\hline $\begin{array}{l}\text { Chryseobacterium sp. CHNTR56 } \\
\text { MYb120 }\end{array}$ & $\begin{array}{l}\text { Sphingobacterium faecium } \\
\text { MYb181 }\end{array}$ & $\begin{array}{l}\text { Comamonas sp. } 12022 \\
\text { MYb131 }\end{array}$ & $\begin{array}{l}\text { Achromobacter sp. F32 } \\
\text { MYb9 }\end{array}$ & E. coli OP50 \\
\hline$d x s$ & $d x s_{-} 1$ & $d x s_{-} 1$ & $d x s_{-} 1$ & $d x s_{-} 1$ \\
\hline \multirow[t]{2}{*}{-} & $d x s \_2$ & $d x s \_2$ & $d x s \_2$ & $d x s \_2$ \\
\hline & & & & $d x s \_3$ \\
\hline$p d x J_{-} 1$ & $p d x J$ & $p d x J$ & $p d x J$ & $p d x J$ \\
\hline$p d x\rfloor \_2$ & - & - & - & - \\
\hline$p d x H$ & $p d x H$ & $p d x H$ & $p d x H$ & $p d x H$ \\
\hline$p d x B_{-} \_1$ & - & $p d \times B$ & - & $p d \times B$ \\
\hline$p d x B \_2$ & - & - & - & - \\
\hline $\operatorname{ser} C_{-} 1$ & $\operatorname{ser} C$ & $\operatorname{ser} C$ & $\operatorname{ser} C$ & $\operatorname{ser} C_{-} 1$ \\
\hline $\operatorname{serC} \_2$ & - & - & - & serC_2 \\
\hline serC_3 & - & - & - & - \\
\hline serC_4 & - & - & - & - \\
\hline$p d x A_{-} 1$ & $p d x A 2$ & $p d x A 2 \_1$ & $p d x A 2 \_1$ & $p d x A$ \\
\hline$p d x A \_2$ & - & $p d x A 2 \_2$ & $p d x A 2 \_2$ & - \\
\hline- & - & $p d x A 2 \_3$ & $p d x A 2 \_3$ & - \\
\hline gapA & gapA_1 & gapA & - & $\begin{array}{l}\text { gapA_1 } \\
\text { epd_1 }\end{array}$ \\
\hline- & gapA_2 & - & - & $\begin{array}{l}\text { gapA_2, } \\
\text { epd_2 }\end{array}$ \\
\hline - & - & $p d x K \neq$ & $p d x K \neq$ & $p d x K \neq$ \\
\hline - & - & $p d x Y \neq$ & - & $p d x y \neq$ \\
\hline
\end{tabular}

Multiple homologs in the specific route of de novo vitamin B6 pathway (D-erythrose 4-P is converted to 3-amino-1-hydroxyacetone 1-P4) for Chryseobacterium sp. CHNTR56 MYb120 (serC_1-4) and Comamonas sp. 12022 MYb131 (pdxA2_1-3) are present, which are indicated with bold. \#: Salvage pathway 
with the presence of E. coli OP50 and vitamin B6 demonstrated significantly higher survival rates (increases from 27 to 58\%) after the midlife stage of the worm, compared to control (Fig. 6). The statistics are shown in Additional file 7. The difference in median and maximum lifespans between these groups was found to be statistically significant $(P=0.0382$ for median lifespan, $P=0.0402$ for maximum lifespan) (Additional file 7). Consequently, constant supplementation of vitamin B6 resulted in a positive effect on worm lifespan. Altogether, these data support that the presence of the native bacterial isolates of interest is likely favored in the worm in order to achieve stable vitamin B6 supply.

\section{Discussion}

In this study, we first exposed C. elegans to certain chemicals $\left(\mathrm{SiO}_{2}\right.$ nanoparticles and juglone) known to cause cellular toxicity through increased oxidative stress by ROS $[19,20]$ and monitored whether colonizing members of the microbiome could offer a beneficial effect to the worm under the stress conditions. Some bacterial isolates indeed provided a beneficial effect as measured by progeny output of the worms in the presence of $\mathrm{SiO}_{2}$ nanoparticles and juglone. Reproductive capacity, based on progeny output, is a measure of $C$. elegans fitness [50]. In our assay, Chryseobacterium sp. CHNTR56 MYb120 and Comamonas sp. 12022 MYb131 were the only bacterial isolates to significantly promote progeny output under the indicated conditions, which suggests that these bacterial isolates provided a benefit to the worm, more precisely against oxidative stress. This observation highlights the positive influence of the microbiome members on worm reproduction (measured by progeny output), as the response to oxidative stress is generally correlated to reduced capacity for reproduction in higher eukaryotes and C. elegans $[18,21,51]$.
After confirming that the two bacterial isolates of interest indeed colonized the worm, we then investigated whether they could influence worm lifespan. The lifespan of C. elegans grown with Comamonas sp. 12022 MYb131 (a native bacterial isolate of the wild isolates of C. elegans) and E. coli OP50 was not found to be statistically different in the present study, although Comamonas DA1877 (relates to Comamonas aquatica) was reported to reduce C. elegans lifespan (about 2-3 days in mean lifespan) compared to the same control bacteria in previous studies $[31,52]$. This could be related to differences of the Comamonas isolates, such as secretion and/ or colonization properties, which appear to play an important role. Different bacterial strains of the same genus vary in their functional effects on their host as described by previous studies [17, 53]. C. elegans grown with Chryseobacterium sp. CHNTR56 MYb120 or with a combination of both Chryseobacterium sp. CHNTR56 MYb120 and Comamonas sp. 12022 MYb131 showed greater survival rates, resulting in an extended lifespan (as maximum lifespan increase by Chryseobacterium sp. CHNTR56 MYb120 and as median and maximum lifespan increases by the combination of the two bacteria isolates), compared to growth with E. coli OP50 alone (Fig. 2, Table 1), highlighting the effects of the microbiome members on worm longevity. Associated upregulation of gst and cyp genes, indicating enhanced cellular detoxification, and downregulation of $p d k-1$ (which leads to less phosphorylation of SGK-1) (Additional file 3), are proposed to explain the increased ratio of progeny output under oxidative stress and the extension of lifespan, most likely through DAF-16 activity (in the absence of experimentally induced toxicity) [54]. Mechanistically, we suggest that the bacteria can trigger the worm's cellular detoxification mechanisms through the release of certain molecules (including ROS) that activate the worm response to induce gst and cyp gene expression.

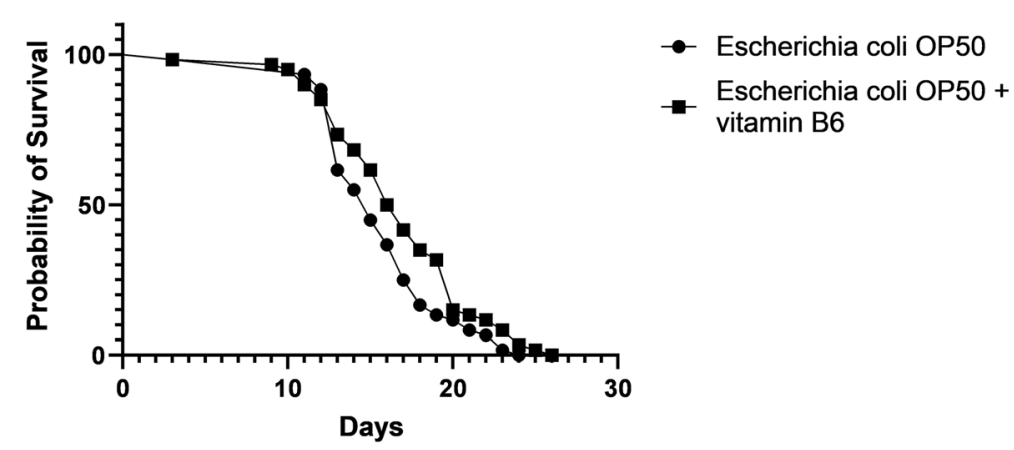

Fig. 6 Survival of the worms grown with E. coli OP50 in the presence or absence of vitamin B6 supplementation over time. Survival curves are shown. Worms grown with E. coli OP50 supplemented with vitamin B6 demonstrated significantly higher median and maximum lifespans, compared to control ( $P=0.0382$ for median lifespan and $P=0.0402$ for maximum lifespan). The concentration of vitamin B6 (pyridoxine hydrochloride) was $100 \mathrm{nM}$ and this experiment was replicated three times 
Nevertheless, the downregulation of the hsp-16.2 gene (a reference gene of oxidative stress [19]) in this study indicates that oxidative stress is eventually suppressed under our experimental conditions.

Although both native bacterial isolates, Chryseobacterium sp. CHNTR56 MYb120 or Comamonas sp. 12022 MYb131, had similar effects on the worm in terms of progeny production under toxicity and transcriptomic changes in the indicated biological pathway activities (Figs. 4 and 5), their individual effect on worm lifespan was not the same. It is possible that the other factors are involved in the observed results obtained from the lifespan assay. These factors could be of technical nature. For example, we measured progeny production in the presence of toxicity under different experimental conditions compared to the lifespan assay. Nevertheless, the observed differences do not change the main conclusion of our study, as highlighted by the synergism of bacterial isolates resulting in worm lifespan extension.

The detected effects in dealing with toxicity in the worms grown with Chryseobacterium sp. CHNTR56 MYb120 or Comamonas sp. 12022 MYb131, but not by the other native bacterial isolates including members from the same phyla of these isolates (Additional file 1), and the upregulation of cellular detoxification responses in the worms grown with the two bacterial isolates, suggest that a bacteria buffering effect in dealing with toxicity was not the reason for our observations, given a recent study using a non-colonizing bacteria such as $E$. coli isolates [55], which shows this effect.

Based on the results shown in the present study, we attributed the observation of the enhanced cellular detoxification to the upregulation of $C$. elegans cysl genes when grown with the isolates (Fig. 7). As cysteine is required for glutathione-mediated cellular detoxification [56-58], we suggest that this is promoted, at least in part, by the bacterial isolates favoring vitamin B6 synthesis, required for cysteine synthesis, as determined by the presence of gene homologs found in their respective genomes. Identification of the multiple $\operatorname{ser} C$ or $p d x A 2$ homologs in the specific route of vitamin B6 de novo synthesis (D-erythrose 4-P is converted to 3-amino-1hydroxyacetone 1-P4) suggests that Chryseobacterium sp. CHNTR56 MYb120 and Comamonas sp. 12022 MYb131 are specialized in the synthesis and expression of vitamin B6, compared to closely related species (analyzed in this study) and E. coli OP50.

The increase in the number of gene homologs related to vitamin B6 synthesis in these bacteria is likely related to adaption to diverse and harsh environmental conditions, in which they may encounter oxidative stress [59]. Specifically, the presence of multiple $p d x B$ or $p d x J$ homologs in Chryseobacterium sp. CHNTR56 MYb120 indicates that the vitamin B6 metabolism is highly critical

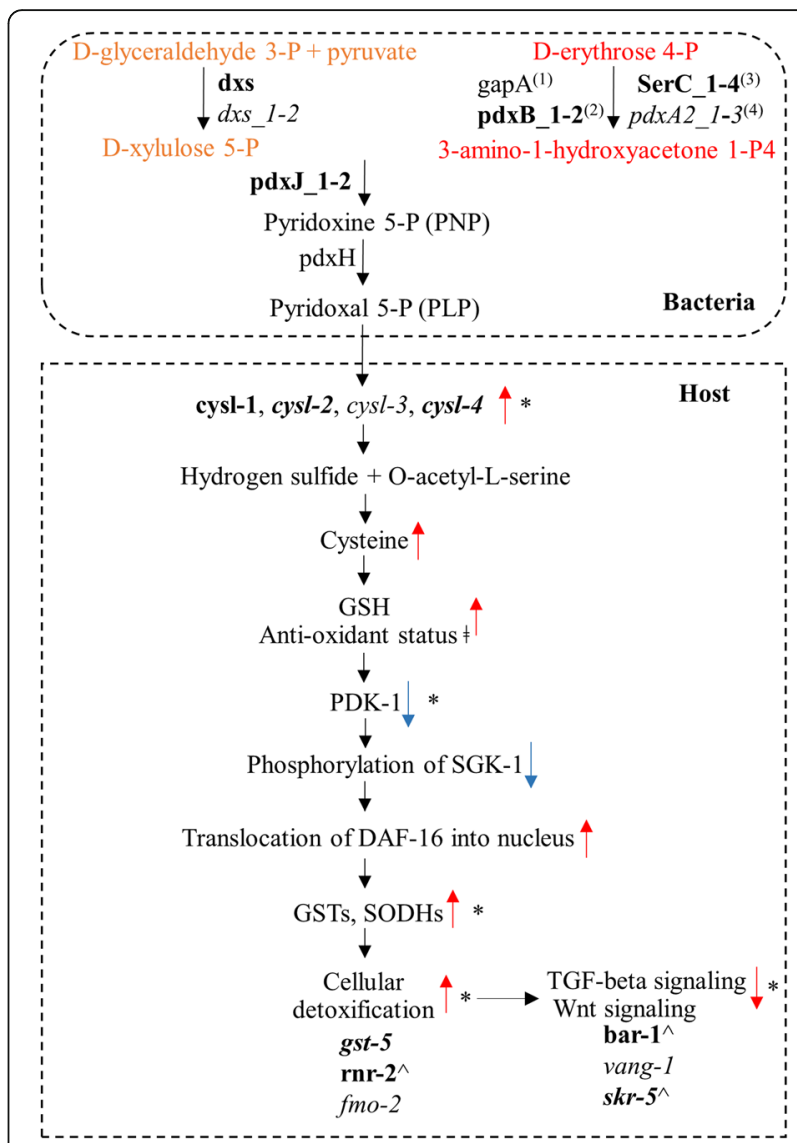

Fig. 7 Proposed model of interactions between the worm and its associated microbiome. The active form of bacterial vitamin B6, pyridoxal-5P (PLP), is a required cofactor of cysteine synthases (cysl) of the worm for the enzyme activity. Identification of multiple homologs (serC_1-4 and pdxA2_1-3) in the specific route of vitamin B6 de novo pathway (conversion of D-erythrose 4-P to 3amino-1-hydroxyacetone 1-P4) in the native bacterial isolates, as determined by nanopore sequencing, and identification of multiple isomers (cysl-1-4) for cysteine synthesis in the host, as determined by RNAseq, demonstrate the critical importance of the interspecies relationship. In this proposed model, vitamin B6 is linked to cellular detoxication through GSTs, which is accompanied with the regulation of TGF-beta and Wnt signaling pathways, where $C$. elegans genes, with human homologs, are regulated. Bacterial genes are highlighted with bold and italic to indicate the relation to Chryseobacterium sp. CHNTR56 MYb120 and Comamonas sp. 12022 MYb131, respectively. The sequential order for the enzymatic steps is indicated with super script in parenthesis. Red arrow indicates up regulation and blue arrow indicates down-regulation. *: confirmed by RNAseq. $\wedge$ : reverse gene expression (compared to the other enriched genes in the indicated pathway). ₹: supported by the downregulation of hsp-16.2 (detected by RNAseq)

in this bacterium and is suggested to help the worm to cope with oxidative stress, compared to worms grown with Comamonas sp. 12022 MYb131 or E. coli OP50. Additionally, available literature also supports our claim that E. coli expresses less vitamin B6 compared to soil bacteria [60]. Based on these findings, the colonization 
effect of the native bacterial isolates was expected to promote stability in vitamin B6 supply at required levels for the worm. Consequently, constant supplementation of NGM plates with vitamin B6 increased worm survival rates (Fig. 6, Additional file 7), thereby further supporting the role of a stable supply of this vitamin in worm physiology. In our colonization experiments, we observed that E. coli OP50 is readily consumed by the worm (within about $2 \mathrm{~h}$ ), therefore it is expected that the worm is not exposed to a constant supply of vitamin B6. Our analysis indicates that supplementing vitamin $\mathrm{B} 6$ to the E. coli OP50 seeded NGM plates on a regular basis appears to mimic the effect of the colonizing native bacterial isolates of interest (having genomes that contain multiple gene homologs in vitamin B6 synthesis), based on the findings of our lifespan experiments. Additionally, this also indicates that the possible consumption of vitamin B6 by E. coli OP50 did not mask the effect of this essential vitamin on the worm.

In the present study, worms grown with Chryseobacterium sp. CHNTR56 MYb120 or Comamonas sp. 12022 MYb131 showed similar patterns of changes in biological pathway activities at the global level, but differential expression of certain genes associated with aging in these pathways ( $r n r-2$, fmo-2, bar-1, vang-1, ragc-1) was found to be specific in the response to each bacterial isolate. This observation may explain the synergistic effect of these two bacterial isolates in terms of promoted longevity of the worm. Conversely, a common gene involved in glutathione-based cellular detoxification mechanisms, gst5 (related to aging in C. elegans and humans), was found to be upregulated in the worms grown with each of the bacterial isolates of interest.

Understanding the effects of the native bacteria on the C. elegans host is a very new research field and we aimed to study this complex field by initiating a broad survey of phenotypes followed by omics analyses. The model we use here is established for wild type C. elegans. C. elegans mutants could not be utilized in recent studies (in terms of focusing on host-microbiota interactions based on native bacterial isolates and their host) [17, 50]. Future studies to establish C. elegans mutants harboring the native bacteria will be very useful. Additionally, native bacterial isolates of C. elegans have been suggested to release small compounds that are vital for the worm host [61]. Therefore, future studies investigating the bacterially produced metabolites would provide valuable information.

\section{Conclusions}

The present study has shown that two bacterial isolates (Chryseobacterium sp. CHNTR56 MYb120 and Comamonas sp. $12022 \mathrm{MYb131)}$ of the native C. elegans microbiome promote worm fitness (as measured by reproductive capacity in the presence of cellular toxicity caused by $\mathrm{SiO}_{2}$ nanoparticles and juglone) and longevity (as illustrated by the synergistic effect of the bacterial isolates). RNAseq and nanopore sequencing suggest that the observed beneficial effect and longevity promotion can be explained, at least in part, by the induction of glutathione-associated cellular detoxification with the upregulation of cysl genes in the worm that favors the colonizing native bacterial isolates with diversity in vitamin B6 de novo synthesis, indicating the importance of vitamin supply. This was confirmed by enhanced survival of C. elegans, especially in the mid and later stages of life, when co-cultured with vitamin B6. In agreement with other studies $[12,13,17,61]$, this study showcases C. elegans as a promising alternative model to study host-microbiome interactions and we expand on this by integrating omics-based analyses.

\section{Methods \\ Study design}

L4-young adult C. elegans, grown with each of the native bacteria species or E. coli OP50, were exposed to chemically-induced toxicities. The progeny produced by the worm were used as the indicator of their fitness or resistance under the challenge. The rest of the experiments were performed independently without exposing the worms to toxicity. The effect of these bacteria on the worm's lifespan was examined. L4-young adult worms grown with the bacteria of interest were subjected to RNAseq, followed by nanopore sequencing of the genomes of these bacteria. Finally, the effect of the metabolite of interest (vitamin B6) was tested on worm lifespan.

\section{Caenorhabditis elegans and bacteria species}

The C. elegans N2 strain (Bristol) and Escherichia coli OP50 were obtained from the Caenorhabditis Genetics Center (CGC) at the University of Minnesota. A total of 16 native different bacterial isolates (listed in Additional file 1) were kindly provided by Prof. Hinrich Schulenburg, Zoological Institute, Evolutionary Ecology and Genetics, Christian-Albrechts-Universität zu Kiel, Kiel, Germany.

\section{Worm maintenance and bacterial culture}

Escherichia coli OP50 and the native bacterial isolates were grown until the bacterial growth reached stationary phase at $37^{\circ} \mathrm{C}$ and at $28^{\circ} \mathrm{C}$ in tryptic soy broth (TSB), respectively. The C. elegans $\mathrm{N} 2$ strain was maintained at $21^{\circ} \mathrm{C}$ in an incubator on nematode growth media (NGM) plates using E. coli OP50. The nematode worms were synchronized using $5.0 \mathrm{ml}$ of alkaline bleach $(16.6 \%, \mathrm{v} / \mathrm{v})$ to kill the adults and to obtain eggs, without any bacterial contamination. Eggs from the adult worms were then washed three times with sterile M9 buffer and 
left overnight on a rocking platform at room temperature for hatching.

\section{Colonization assay}

Bacterial colonization inside the worm was evaluated based on a previously published method [25]. Firstly, a trial was carried out to determine the antibiotic susceptibility of the bacterial isolates $(n=16)$ by streaking each bacterial isolate on each TSB plate containing various antibiotics such as ampicillin $(100 \mu \mathrm{g} / \mathrm{ml})$, kanamycin $(50 \mu \mathrm{g} / \mathrm{ml})$, tetracycline $(10 \mu \mathrm{g} / \mathrm{ml})$, or mixtures (Additional file 1). Approximately 200 synchronized L1 worms were grown for $48 \mathrm{~h}$ at $21^{\circ} \mathrm{C}$ to the L4-young adult worm stage with native bacterial isolates (except Ochrobactrum sp. R-26465 MYb71 and Stenotrophomonas sp. R-41388 MYb57, Achromobacter sp. F32 MYb9 because of resistance to all the antibiotic treatments in this study), at equal concentrations of bacteria based on $\mathrm{OD}_{595}=\sim 5$, on NGM plates. The grown worms $(n=20)$ were then transferred to bacteria-free NGM plates including the indicated antibiotics, of which, bacterial isolates are susceptible (Additional file 1) for $24 \mathrm{~h}$ for surface sterilization of the worms. The worms were washed with M9 buffer five times, disrupted and placed on TSB agar plates to recover bacteria.

\section{Progeny assay under chemically-induced toxicity}

Approximately 200 synchronized L1 of C. elegans were grown to the L4-young adult stage on NGM plates seeded with E. coli OP50 or one of the native bacterial isolates $(n=16)$ (at equal concentrations of bacteria based on $\mathrm{OD}_{595}=\sim 5$ ). The worms were visually inspected as being L4-young adults before being run through the experiment. Five L4-young adult hermaphrodites were transferred to an individual well in quadruplicate of a 12-well plate containing S-medium [62] supplemented with either 0 (control, only S-medium) or $50 \mu \mathrm{g} / \mathrm{ml}$ of silicon dioxide nanoparticles $\left(\mathrm{SiO}_{2}\right)$ [18] and E. coli OP50 or one of the native bacteria species at a final concentration of $\mathrm{OD}_{595}=\sim 1$. The L4-young adults were then incubated for $96 \mathrm{~h}$ at $21^{\circ} \mathrm{C}$, and resulting larvae were counted by dilution. The ratio of progeny was determined based on the percentage of larvae number in the $\mathrm{SiO}_{2}$ treatment to larvae number in control for the worms grown with each tested bacterium. For the phenotypes showing a higher ratio of progeny ( $>50 \%$ of the control value), the same protocol was followed by using $\mathrm{SiO}_{2}$ at the indicated concentration or $50 \mu \mathrm{M}$ of juglone (5-hydroxy-1,4-naphthoquinone, prepared in ethanol), which was repeated in triplicate. In both initial and final screenings, the progeny of output for E. coli OP50 in each well of the plate was measured. We chose $\mathrm{SiO}_{2}$ and juglone as both chemicals have been shown to mediate their toxic effects by causing cellular oxidative stress and suppress detoxification mechanisms involving the expression/activity of GSTs [19, 20, 23, 63].

\section{Lifespan analysis}

Approximately 200 synchronized L1 of C. elegans were grown to the L4-young adult stage on NGM plates seeded with E. coli OP50 or the bacteria of interest (Chryseobacterium sp. CHNTR56 MYb120 or Comamonas sp. 12022 MYb131) (at equal concentrations of bacteria based on $\left.\mathrm{OD}_{595}=\sim 5\right)$. Worms $(n=20$ for each group) were transferred to new NGM plates seeded with the corresponding bacteria each day using a sterile platinum wire and alive worms were counted based on motility (death of worms was verified by probing with a platinum wire) [64]. To understand the effect of vitamin B6 in lifespan, a similar protocol was followed with slight modifications; E. coli OP50 was the bacterial food source and NGM plates contained $25 \mu \mathrm{M}$ 5-Fluoro-2'-deoxyuridine (FUDR was added at the days 2 and 6 to stop progeny) plus $100 \mathrm{nM}$ pyridoxine hydrochloride (media stable version of vitamin B6; prepared in M9 buffer as not to change the $\mathrm{pH}$ of the NGM media), and worms ( $n=20$ for each group) were transferred to fresh NGM plates with the supplementation of vitamin B6 or M9 buffer alone (as control) every 2-3 days. C. elegans possesses two genes encoding putative pyridoxal kinase (PDXK-1) and putative pyridoxamine 5'-phosphate oxidase (F57B9.1), converting pyridoxine into pyridoxine $5^{\prime}$-phosphate and pyridoxine 5 '-phosphate to pyridoxal 5 -phosphate (active form), respectively (UniProt; www. uniprot.org) [48]. Each experiment (measuring the effect of native bacteria or the effect of vitamin B6 on lifespan) was repeated in triplicate.

\section{Total RNA extraction from C. elegans for RNAseq}

Approximately 200 synchronized L1 of C. elegans were grown to the L4-young adult stage on NGM plates seeded with $E$. coli OP50 or bacterium of interest (Chryseobacterium sp. CHNTR56 MYb120 or Comamonas sp. 12022 MYb131), at equal concentrations of bacteria based on $\mathrm{OD}_{595}=\sim 5$, at $21^{\circ} \mathrm{C}$, in triplicate. The NGM plates containing L4-young adult stage worms were washed twice with M9 buffer and centrifuged at $1000 \mathrm{~g}$ for $2 \mathrm{~min}$. A total of $200 \mu \mathrm{l}$ of Trizol (Ambion, USA) was added to the worm pellet. The worm pellet was snap-frozen in liquid nitrogen, which was followed by a quick thaw. These two steps were repeated once. Total RNA from the homogenate was extracted using the Direct-zol RNA miniprep kit (Zymo Research, USA) according to the manufacturer's instructions. Quantity and purity of total RNA were analysed using a spectrophotometer (ND-1000, NanoDrop). The RNA samples were sent to the McGill University and Génome Québec Innovation Centre (https:// gqinnovationcenter.com) under recommended conditions 
for quality analysis of total RNA with Bioanalyzer (Agilent) and single-end read (100 base) next generation sequencing of RNA using HiSeq 2500 (Illumina) was performed.

\section{RNAseq data analysis}

Raw data for all samples were obtained in fastq file format from the McGill University and Génome Québec Innovation Centre. Data analysis was carried out using NetworkAnalyst (https://www.networkanalyst.ca) [33]. Read quality was checked with FASTQC (version 0.72) and adapter related sequences were removed using Trim Galore (version 0.4.3.1) (https://www.bioinformatics.babraham.ac.uk/projects/). The genome sequence of $C$. elegans and GTF file (Caenorhabditis elegans.WBcel235.94.gtf) was obtained from ENSEMBL (https://www.ensembl.org/). Reads were aligned to the C. elegans genome with HISAT2 (Galaxy version 2.1.0) [65] and read counts were obtained using HTSeq (version 0.9.1) [66] with the intersection-strict mode. For downstream analysis, sequence data was uploaded to NetworkAnalyst. Sequences with low variance $(15 \%)$ and low abundance $(n<4)$ counts were removed. Data were normalized based on trimmed mean of $\mathrm{M}$ values and sample distribution was determined by principal component analysis. Differential gene expression analysis was performed using edgeR [67] and statistical significance was defined by the FDR value less than 0.05 . For significant gene analysis, overrepresentation enrichment network and heatmap clustering were performed. Biological processes or pathways were considered significant if their $P$ values were less than 0.05 from the enrichment analysis. Heatmap visualization was performed with pheatmap function in $\mathrm{R}$.

\section{Meta-analysis}

All the differentially expressed genes (DEGs, FDR $<0.05$ ) in the worms grown with Chryseobacterium sp. CHNT R56 MYb120 or Comamonas sp.12022 MYb131 (compared to the worms grown with E. coli OP50) were searched against aging associated $C$. elegans and human genes using Human Ageing Genomic Resources (HAGR) (https://genomics.senescence.info/) [40]. The aging related genes in the database were defined mainly based on the previous experimental data and biological links (using the indicated data) for C. elegans and human, respectively. Moreover, $C$. elegans genes that were associated with aging but not with their human homologs, which were not reported in the database list, were further searched using the data from Ortholist2 [41].

\section{Genomic DNA extraction of bacteria and nanopore sequencing}

E. coli OP50, Chryseobacterium sp. CHNTR56 MYb120 and Comamonas sp. $12022 \mathrm{MYb131}$ were grown in TSB broth at $28{ }^{\circ} \mathrm{C}$ until the growth $\mathrm{OD}_{595}$ reached a value of 3. Bacteria were centrifuged at $4000 \mathrm{rpm}$ for $10 \mathrm{~min}$ and supernatants were taken off. Genomic DNA from bacteria were extracted using ZymoBIOMICS DNA Miniprep Kit (Zymo Research). DNA quality and quantity were checked with a spectrophotometer (NanoDrop) and Qubit dsDNA BR Assay Kit (Invitrogen), respectively. For comparative purposes, genomic DNA from the other bacteria genetically close to the native bacteria of interest (Sphingobacterium faecium MYb181 and Achromobacter sp. F32 MYb9; determined based on relevant $16 \mathrm{~S}$ ribosomal RNA sequences from NCBI using MUSCLE, European Bioinformatics Institute, https:// www.ebi.ac.uk) was obtained with the same approach for sequencing. DNA library preparation for each sample including DNA repair, end-prep and adapter ligation steps was carried out using the required reagents (FFPE DNA Repair Mix, Ultra II End Repair/dA-Tailing and Quick Ligation Modules, and Blunt/TA Ligase Master Mix) from New England Biolabs as described in the sequencing protocol provided by Oxford Nanopore Technologies. All DNA clean-up steps were done with Agencourt AMPure XP beads (Beckman Coulter) using a magnetic stand (GE Healthcare). Samples were barcoded with Native Barcoding Expansion kit [EXP-NBD104, Oxford Nanopore Technologies (ONT)]. Pooled DNA of the samples with different barcodes at equal concentrations were prepared for sequencing with Ligation Sequencing Kit (SQK-LSK109, ONT) and loaded onto a flowcell (FLO-MN106, ONT) which is connected to the sequencing device, MinION (ONT), and whole genome longread sequencing was performed based on the protocol.

\section{Nanopore sequencing data analysis}

After the sequencing run $(72 \mathrm{~h})$ was completed with MinKNOW Core (v3.6.5, ONT) on a laptop computer, Fast5 data was converted to Fastq data with Guppy (v3.4.5, ONT). Reads were demultiplexed by qcat (v1.1.0) (https:// github.com/nanoporetech/qcat). Quality filtering and read trimming were carried out with Filtlong (v0.2.0) (https:// github.com/rrwick/Filtlong) and Porechop (v0.2.4) (https:// github.com/rrwick/Porechop), respectively. The obtained sequences were assembled by Flye (v2.7) [68], and coding sequences were determined and annotated by Prokka (v1.14.6) [69]. The outcome of each sequence assembly, genome coverage, coding sequences and gene symbols was reported for each bacterium analyzed. Details in gene functions and enzyme reactions were searched using the data from UniProt (www.uniprot.org) [48]. Genes and metabolites in the vitamin B6 synthesis pathway for bacteria were obtained from previous studies [70, 71].

\section{Statistical analysis}

The group differences for the ratio of progeny output was examined by ANOVA with Tukey's HSD in R, respectively. 
For comparison of median lifespan, statistical differences in survival curves were evaluated by log-rank (Mantel-Cox) test using GraphPad Prism (v8.4.3). Comparison of maximum lifespan (defined as $10 \%$ of the longest-lived worms) was carried out using Student's t test [72] with the same software. A $P$ value less than 0.05 was accepted as statistically significant.

\section{Abbreviations}

CGC: Caenorhabditis Genetics Center; CYPs: The cytochrome P450 family genes; DEGs: Differentially expressed genes; FISH: Fluorescence In Situ Hybridization; FUDR: 5-Fluoro-2'-deoxyuridine; GO: Gene ontology; GSTs: Glutathione S-transferases; HAGR: Human Ageing Genomic Resources; KEGG: Kyoto Encyclopedia of Genes and Genomes; NCBI: The National Center for Biotechnology Information; NGM: Nematode Growth Media; PCA: Principal component analysis; RNAseq: RNA sequencing; SiO2: Silicon dioxide; TSB: Tryptic soy broth; UniProt: The Universal Protein Resource

\section{Supplementary Information}

The online version contains supplementary material available at https://doi. org/10.1186/s12864-021-07695-y.

Additional file 1: List of native bacterial isolates of $C$. elegans and susceptibility to antibiotics. A total of 16 native bacterial isolates, used in this study, is shown with phylum to family information (based on NCBI) and their growth/non-growth status under certain antibiotic treatments.

\section{Additional file 2: Figure S1. Colonization of $C$. elegans by the} native bacterial isolates of interest. Bacterial colonies from $C$. elegans grown with E. coli OP50 or native bacterial isolates (Chryseobacterium sp. CHNTR56 MYb120 and Comamonas sp. 12022 MYb131), after surface sterilization of the worms by the indicated antibiotics and without bacterial food source supplementation for $24 \mathrm{~h}$, are shown.

Additional file 3: Differentially expressed genes between worms grown with different bacterial isolates. Differentially expressed genes between worms grown with E. coli OP50 and Chryseobacterium sp. CHNT R56 MYb120 or Comamonas sp. 12022 MYb131 were determined by edge $R$ and ranked based on FDR.

Additional file 4: Figure S2. Venn diagram. Statistically significant differentially expressed genes with fold change greater than 1 for $C$. elegans grown with Chryseobacterium sp. CHNTR56 MYb120 or Comamonas sp. 12022 MYb131, compared to E. coli OP50, are shown.

Additional file 5: Figure S3. Heatmap for the regulation of cytochrome P450 family genes (CYPs). Most CYPs were upregulated in worms grown with Chryseobacterium sp. CHNTR56 MYb120 (a) or Comamonas sp. 12022 MYb131 (b), in comparison with E. coli OP50.

Additional file 6: Nanopore sequencing of bacteria genomes. The number of the contigs, length and annotated genes for each bacterial isolate and E. coli OP50 are shown.

Additional file 7: Lifespan of the worms grown with E. coli OP50 in the presence or absence of vitamin B6. Lifespan values and related statistics for the worms grown with E. coli OP50 alone or E. coli OP50 plus vitamin B6 are shown. Median and maximum lifespans of worms grown with E. coli OP50 supplemented with vitamin B6 were significantly higher, compared to control $(P=0.0382$ for median lifespan and $P=0.0402$ for maximum lifespan). No worms were censored.

\section{Acknowledgements}

We kindly thank Prof. Hinrich Schulenburg, Zoological Institute, Evolutionary Ecology and Genetics, Christian-Albrechts-Universität zu Kiel, Kiel, Germany, for providing the native bacterial isolates.

\section{Authors' contributions}

This study was designed by O.H. and J.X. O.H. and C.V. carried out the toxicity assays and F.K. assisted with the wet laboratory work. Total RNA extraction of the worms and RNAseq data analysis and genomic bacteria extraction and nanopore sequencing were performed by O.H. J.X. supervised this study and O.H., C.V. and J.X. wrote this manuscript. All authors have read and approved the manuscript.

\section{Funding}

This study was funded by the Natural Sciences and Engineering Research Council of Canada (NSERC) Discovery Grant and the Canada Research Chairs (CRC) program.

Availability of data and materials

The RNAseq dataset generated and analyzed in this study is available in the $\mathrm{NCBI}$ Gene Expression Omnibus (GEO) database repository, with the accession number GSE143794. The nanopore sequencing data is available in the NCBI Sequence Read Archive (SRA), with the accession number PRJNA663603.

\section{Declarations}

Ethics approval and consent to participate

Not applicable.

\section{Consent for publication}

Not applicable.

\section{Competing interests}

The authors declare that they have no competing interests.

Received: 19 November 2020 Accepted: 10 May 2021

Published online: 19 May 2021

References

1. Caballero S, Kim S, Carter RA, Leiner IM, Susac B, Miller L, Kim GJ, Ling L, Pamer EG: Cooperating commensals restore colonization resistance to Vancomycin-resistant enterococcus faecium. Cell Host Microbe 2017, 21(5): 592-602 e594, doi: https://doi.org/10.1016/j.chom.2017.04.002.

2. Ivory $K$, Chambers SJ, Pin C, Prieto E, Arques JL, Nicoletti C. Oral delivery of Lactobacillus casei Shirota modifies allergen-induced immune responses in allergic rhinitis. Clin Exp Allergy. 2008;38(8):1282-9. https://doi.org/10.1111/ j.1365-2222.2008.03025.x.

3. Greenblum S, Turnbaugh PJ, Borenstein E. Metagenomic systems biology of the human gut microbiome reveals topological shifts associated with obesity and inflammatory bowel disease. Proc Natl Acad Sci U S A. 2012; 109(2):594-9. https://doi.org/10.1073/pnas.1116053109.

4. Eloe-Fadrosh EA, Rasko DA. The human microbiome: from symbiosis to pathogenesis. Annu Rev Med. 2013;64(1):145-63. https://doi.org/10.1146/a nnurev-med-010312-133513.

5. Konig MF. The microbiome in autoimmune rheumatic disease. Best Pract Res Clin Rheumatol. 2020;34(1):101473. https://doi.org/10.1016/j.berh.2019.1 01473.

6. Dekaboruah E, Suryavanshi MV, Chettri D, Verma AK. Human microbiome: an academic update on human body site specific surveillance and its possible role. Arch Microbiol. 2020;202(8):2147-67. https://doi.org/10.1007/ s00203-020-01931-x

7. Douglas AE. Simple animal models for microbiome research. Nat Rev Microbiol. 2019:17(12):764-75. https://doi.org/10.1038/s41579-019-0242-1.

8. Kostic AD, Howitt MR, Garrett WS. Exploring host-microbiota interactions in animal models and humans. Genes Dev. 2013;27(7):701-18. https://doi.org/1 $0.1101 /$ gad.212522.112

9. Arbuthnott D, Levin TC, Promislow DE. The impacts of Wolbachia and the microbiome on mate choice in Drosophila melanogaster. J Evol Biol. 2016; 29(2):461-8. https://doi.org/10.1111/jeb.12788.

10. Trinder M, Daisley BA, Dube JS, Reid G. Drosophila melanogaster as a highthroughput model for host-microbiota interactions. Front Microbiol. 2017:8: 751. https://doi.org/10.3389/fmicb.2017.00751

11. Watnick Pl, Jugder BE. Microbial control of intestinal homeostasis via Enteroendocrine cell innate immune signaling. Trends Microbiol. 2020;28(2): 141-9. https://doi.org/10.1016/j.tim.2019.09.005.

12. Dirksen P, Marsh SA, Braker I, Heitland N, Wagner S, Nakad R, et al. The native microbiome of the nematode Caenorhabditis elegans: gateway to a new host-microbiome model. BMC Biol. 2016;14(1):38. https://doi.org/10.11 86/s12915-016-0258-1. 
13. Samuel BS, Rowedder H, Braendle C, Felix MA, Ruvkun G. Caenorhabditis elegans responses to bacteria from its natural habitats. Proc Natl Acad Sci U S A. 2016;113(27):E3941-9. https://doi.org/10.1073/pnas.1607183113.

14. Zhang F, Berg M, Dierking K, Felix MA, Shapira M, Samuel BS, et al. Caenorhabditis elegans as a model for microbiome research. Front Microbiol. 2017:8:485.

15. Vaiserman AM, Koliada AK, Marotta F. Gut microbiota: a player in aging and a target for anti-aging intervention. Ageing Res Rev. 2017;35:36-45. https:// doi.org/10.1016/j.arr.2017.01.001.

16. Cassidy L, Petersen C, Treitz C, Dierking K, Schulenburg H, Leippe M, et al. The Caenorhabditis elegans proteome response to naturally associated microbiome members of the genus Ochrobactrum. Proteomics. 2018;18(8): e1700426. https://doi.org/10.1002/pmic.201700426

17. Yang W, Petersen C, Pees B, Zimmermann J, Waschina S, Dirksen P, et al. The inducible response of the nematode Caenorhabditis elegans to members of its natural microbiota across development and adult life. Front Microbiol. 2019;10:1793. https://doi.org/10.3389/fmicb.2019.01793.

18. Viau C, Hacariz O, Karimian F, Xia J. Comprehensive phenotyping and transcriptome profiling to study nanotoxicity in C elegans. PeerJ. 2020;8: e8684.

19. Hartwig K, Heidler T, Moch J, Daniel H, Wenzel U. Feeding a ROS-generator to Caenorhabditis elegans leads to increased expression of small heat shock protein HSP-16.2 and hormesis. Genes Nutr. 2009;4(1):59-67. https://doi. org/10.1007/s12263-009-0113-x.

20. Park EJ, Park K. Oxidative stress and pro-inflammatory responses induced by silica nanoparticles in vivo and in vitro. Toxicol Lett. 2009;184(1):18-25. https://doi.org/10.1016/j.toxlet.2008.10.012.

21. Aitken RJ. Impact of oxidative stress on male and female germ cells: implications for fertility. Reproduction. 2020;159(4):R189-201. https://doi. org/10.1530/REP-19-0452.

22. Gong C, Tao G, Yang L, Liu J, He H, Zhuang Z. The role of reactive oxygen species in silicon dioxide nanoparticle-induced cytotoxicity and DNA damage in HaCaT cells. Mol Biol Rep. 2012;39(4):4915-25. https://doi.org/1 0.1007/s11033-011-1287-z.

23. Shang XF, Liu YQ, Guo X, Miao XL, Chen C, Zhang JX, et al. Application of sustainable natural resources in agriculture: Acaricidal and enzyme inhibitory activities of Naphthoquinones and their analogs against Psoroptes cuniculi. Sci Rep. 2018;8(1):1609. https://doi.org/10.1038/s41598-01 8-19964-0.

24. Khanna P, Ong C, Bay BH, Baeg GH. Nanotoxicity: an interplay of oxidative stress, inflammation and cell death. Nanomaterials (Basel). 2015;5(3):1163-80. https://doi.org/10.3390/nano5031163.

25. Han B, Sivaramakrishnan P, Lin CJ, Neve IAA, He J, Tay LWR, Sowa JN, Sizovs A, Du G, Wang J et al: Microbial genetic composition tunes host longevity. Cell 2017, 169(7):1249-1262 e1213, doi: https://doi.org/10.1016/j.cell.2017.05. 036.

26. Hwang SB, Choi JG, Wei S, Park BJ, Chelliah R, Oh DH. In vivo screening platform for Shiga toxin-producing Escherichia coli (STEC) using Caenorhabditis elegans as a model. PLoS One. 2018;13(2):e0193277. https:// doi.org/10.1371/journal.pone.0193277.

27. Tullet JM, Araiz C, Sanders MJ, Au C, Benedetto A, Papatheodorou I, et al. DAF-16/FoxO directly regulates an atypical AMP-activated protein kinase gamma isoform to mediate the effects of insulin/IGF-1 signaling on aging in Caenorhabditis elegans. PLoS Genet. 2014;10(2):e1004109. https://doi. org/10.1371/journal.pgen.1004109.

28. Liggett MR, Hoy MJ, Mastroianni M, Mondoux MA. High-glucose diets have sex-specific effects on aging in C. elegans: toxic to hermaphrodites but beneficial to males. Aging (Albany NY). 2015;7(6):383-8.

29. Sellegounder D, Liu Y, Wibisono P, Chen CH, Leap D, Sun J. Neuronal GPCR NPR-8 regulates $C$. elegans defense against pathogen infection. Sci Adv. 2019;5(11):eaaw4717.

30. Wiegant FA, Surinova S, Ytsma E, Langelaar-Makkinje M, Wikman G, Post JA. Plant adaptogens increase lifespan and stress resistance in $C$. elegans. Biogerontology. 2009;10(1):27-42. https://doi.org/10.1007/s1 0522-008-9151-9.

31. Watson E, MacNeil LT, Ritter AD, Yilmaz LS, Rosebrock AP, Caudy AA, et al. Interspecies systems biology uncovers metabolites Affecting C. elegans gene expression and life history traits. Cell. 2014;156(6):1336-7. https://doi. org/10.1016/j.cell.2014.02.036.

32. De Magalhaes Filho CD, Henriquez B, Seah NE, Evans RM, Lapierre LR, Dillin A. Visible light reduces C. elegans longevity. Nat Commun. 2018;9(1):927.
33. Zhou G, Soufan O, Ewald J, Hancock REW, Basu N, Xia J. NetworkAnalyst 3.0: a visual analytics platform for comprehensive gene expression profiling and meta-analysis. Nucleic Acids Res. 2019;47(W1):W234-41. https://doi.org/10.1 093/nar/gkz240.

34. Murphy CT, McCarroll SA, Bargmann Cl, Fraser A, Kamath RS, Ahringer J, et al. Genes that act downstream of DAF-16 to influence the lifespan of Caenorhabditis elegans. Nature. 2003;424(6946):277-83. https://doi.org/10.1 038/nature01789.

35. McElwee JJ, Schuster E, Blanc E, Piper MD, Thomas JH, Patel DS, et al, Evolutionary conservation of regulated longevity assurance mechanisms. Genome Biol. 2007;8(7):R132. https://doi.org/10.1186/gb-2007-8-7-r132.

36. McElwee JJ, Schuster E, Blanc E, Thomas JH, Gems D. Shared transcriptional signature in Caenorhabditis elegans Dauer larvae and long-lived daf-2 mutants implicates detoxification system in longevity assurance. J Biol Chem. 2004;279(43):44533-43. https://doi.org/10.1074/jbc.M406207200.

37. Depuydt G, Xie F, Petyuk VA, Smolders A, Brewer HM, Camp DG 2nd, et al. LC-MS proteomics analysis of the insulin/IGF-1-deficient Caenorhabditis elegans daf-2(e1370) mutant reveals extensive restructuring of intermediary metabolism. J Proteome Res. 2014;13(4):1938-56. https://doi.org/10.1021/pr4 $01081 \mathrm{~b}$

38. Chen AT, Guo C, Itani OA, Budaitis BG, Williams TW, Hopkins CE, et al. Longevity genes revealed by integrative analysis of isoform-specific daf-16/ FoxO mutants of Caenorhabditis elegans. Genetics. 2015;201(2):613-29. https://doi.org/10.1534/genetics.115.177998.

39. Spanier $B$, Rubio-Aliaga I, Hu H, Daniel H. Altered signalling from germline to intestine pushes daf-2;pept-1 Caenorhabditis elegans into extreme longevity. Aging Cell. 2010;9(4):636-46. https://doi.org/10.1111/j.1474-9726.2 010.00591.x.

40. Tacutu R, Thornton D, Johnson E, Budovsky A, Barardo D, Craig T, et al. Human ageing genomic resources: new and updated databases. Nucleic Acids Res. 2018;46(D1):D1083-90. https://doi.org/10.1093/nar/gkx1042.

41. Kim W, Underwood RS, Greenwald I, Shaye DD. OrthoList 2: a new comparative genomic analysis of human and Caenorhabditis elegans genes. Genetics. 2018;210(2):445-61. https://doi.org/10.1534/genetics.118.301307.

42. Guengerich FP. Cytochrome p450 and chemical toxicology. Chem Res Toxicol. 2008:21(1):70-83. https://doi.org/10.1021/tx700079z.

43. Hayes JD, Flanagan JU, Jowsey IR. Glutathione transferases. Annu Rev Pharmacol Toxicol. 2005;45(1):51-88. https://doi.org/10.1146/annurev.pha rmtox.45.120403.095857.

44. Phang-Lyn S, Llerena VA. Biochemistry, Biotransformation. Treasure Island: StatPearls; 2020

45. Shaw WM, Luo S, Landis J, Ashraf J, Murphy CT. The C. elegans TGF-beta Dauer pathway regulates longevity via insulin signaling. Curr Biol. 2007; 17(19):1635-45. https://doi.org/10.1016/j.cub.2007.08.058.

46. Gao AW, Smith RL, van Weeghel M, Kamble R, Janssens GE, Houtkooper RH. Identification of key pathways and metabolic fingerprints of longevity in C. elegans. Exp Gerontol. 2018;113:128-40. https://doi.org/10.1016/j.exger.201 8.10.003.

47. Oliveira RP, Porter Abate J, Dilks K, Landis J, Ashraf J, Murphy CT, et al. Condition-adapted stress and longevity gene regulation by Caenorhabditis elegans SKN-1/Nrf. Aging Cell. 2009;8(5):524-41. https://doi.org/10.1111/j.14 74-9726.2009.00501.x.

48. The UniProt C. UniProt: the universal protein knowledgebase. Nucleic Acids Res. 2017:45(D1):D158-69.

49. Sprenger GA, Schorken U, Wiegert T, Grolle S, de Graaf AA, Taylor SV, et al. Identification of a thiamin-dependent synthase in Escherichia coli required for the formation of the 1-deoxy-D-xylulose 5-phosphate precursor to isoprenoids, thiamin, and pyridoxol. Proc Natl Acad Sci U S A. 1997;94(24): 12857-62. https://doi.org/10.1073/pnas.94.24.12857.

50. Kissoyan KAB, Drechsler M, Stange EL, Zimmermann J, Kaleta C, Bode HB, Dierking K: Natural C. elegans microbiota protects against infection via production of a cyclic Lipopeptide of the Viscosin group. Curr Biol 2019, 29(6):1030-1037 e1035, doi: https://doi.org/10.1016/j.cub.2019.01.050.

51. Kumsta C, Thamsen M, Jakob U. Effects of oxidative stress on behavior, physiology, and the redox thiol proteome of Caenorhabditis elegans. Antioxid Redox Signal. 2011;14(6):1023-37. https://doi.org/10.1089/ars.2010.3203.

52. MacNeil LT, Watson E, Arda HE, Zhu LJ, Walhout AJ. Diet-induced developmental acceleration independent of TOR and insulin in C. elegans. Cell. 2013;153(1):240-52. https://doi.org/10.1016/j.cell.2013.02.049.

53. Montalvo-Katz S, Huang H, Appel MD, Berg M, Shapira M. Association with soil bacteria enhances p38-dependent infection resistance in Caenorhabditis 
elegans. Infect Immun. 2013;81 (2):514-20. https://doi.org/10.1128/IAl. 00653-12.

54. Kim J, Ishihara N, Lee TR. A DAF-16/FoxO3a-dependent longevity signal is initiated by antioxidants. Biofactors. 2014;40(2):247-57. https://doi.org/10.1 002/biof.1146.

55. Schiffer JA, Servello FA, Heath WR, Amrit FRG, Stumbur SV, Eder M, et al. Caenorhabditis elegans processes sensory information to choose between freeloading and self-defense strategies. Elife. 2020;9. https://doi.org/10.7554/ elife.56186.

56. Pizzorno J. Glutathione! Integr Med (Encinitas). 2014;13(1):8-12.

57. Lyons J, Rauh-Pfeiffer A, Yu YM, Lu XM, Zurakowski D, Tompkins RG, et al. Blood glutathione synthesis rates in healthy adults receiving a sulfur amino acid-free diet. Proc Natl Acad Sci U S A. 2000;97(10):5071-6. https://doi.org/1 0.1073/pnas.090083297.

58. Wu G, Fang YZ, Yang S, Lupton JR, Turner ND. Glutathione metabolism and its implications for health. J Nutr. 2004;134(3):489-92. https://doi.org/10.1 093/jn/134.3.489.

59. Bratlie MS, Johansen J, Sherman BT, Huang da W, Lempicki RA, Drablos F. Gene duplications in prokaryotes can be associated with environmental adaptation. BMC Genomics. 2010;11:588.

60. Dempsey WB. Biosynthesis of vitamin B6 by bacteria. J Bacteriol. 1967;93(3): 1179-80. https://doi.org/10.1128/JB.93.3.1179-1180.1967.

61. Zimmermann J, Obeng N, Yang W, Pees B, Petersen C, Waschina S, et al. The functional repertoire contained within the native microbiota of the model nematode Caenorhabditis elegans. ISME J. 2019;14:26-38.

62. Stiernagle T. Maintenance of C. elegans. WormBook. 2006:1-11.

63. Chatterjee N, Jeong J, Yoon D, Kim S, Choi J. Global metabolomics approach in in vitro and in vivo models reveals hepatic glutathione depletion induced by amorphous silica nanoparticles. Chem Biol Interact. 2018;293:100-6. https://doi.org/10.1016/j.cbi.2018.07.013.

64. Gems D, Riddle DL. Defining wild-type life span in Caenorhabditis elegans. J Gerontol A Biol Sci Med Sci. 2000;55(5):B215-9. https://doi.org/10.1093/ gerona/55.5.B215.

65. Kim D, Langmead B, Salzberg SL. HISAT: a fast spliced aligner with low memory requirements. Nat Methods. 2015;12(4):357-60. https://doi.org/10.1 038/nmeth.3317.

66. Anders S, Pyl PT, Huber W. HTSeq--a Python framework to work with highthroughput sequencing data. Bioinformatics. 2015;31(2):166-9. https://doi. org/10.1093/bioinformatics/btu638.

67. Robinson MD, McCarthy DJ, Smyth GK. edgeR: a bioconductor package for differential expression analysis of digital gene expression data. Bioinformatics. 2010;26(1):139-40. https://doi.org/10.1093/bioinformatics/ btp616.

68. Kolmogorov M, Yuan J, Lin Y, Pevzner PA. Assembly of long, error-prone reads using repeat graphs. Nat Biotechnol. 2019;37(5):540-6. https://doi. org/10.1038/s41587-019-0072-8

69. Seemann T. Prokka: rapid prokaryotic genome annotation. Bioinformatics. 2014;30(14):2068-9. https://doi.org/10.1093/bioinformatics/btu153.

70. Scott TA, Quintaneiro LM, Norvaisas P, Lui PP, Wilson MP, Leung KY, HerreraDominguez L, Sudiwala S, Pessia A, Clayton PT, Bryson K, Velagapudi V, Mills $P B$, Typas A, Greene NDE, Cabreiro F: Host-microbe co-metabolism dictates Cancer drug efficacy in C. elegans. Cell 2017, 169(3):442-456 e418, doi: https://doi.org/10.1016/j.cell.2017.03.040.

71. Michalkova V, Benoit JB, Weiss BL, Attardo GM, Aksoy S. Vitamin B6 generated by obligate symbionts is critical for maintaining proline homeostasis and fecundity in tsetse flies. Appl Environ Microbiol. 2014; 80(18):5844-53. https://doi.org/10.1128/AEM.01150-14.

72. Lee GD, Wilson MA, Zhu M, Wolkow CA, de Cabo R, Ingram DK, et al. Dietary deprivation extends lifespan in Caenorhabditis elegans. Aging Cell. 2006;5(6):515-24. https://doi.org/10.1111/j.1474-9726.2006.00241.x.

\section{Publisher's Note}

Springer Nature remains neutral with regard to jurisdictional claims in published maps and institutional affiliations.

Ready to submit your research? Choose BMC and benefit from:

- fast, convenient online submission

- thorough peer review by experienced researchers in your field

- rapid publication on acceptance

- support for research data, including large and complex data types

- gold Open Access which fosters wider collaboration and increased citations

- maximum visibility for your research: over $100 \mathrm{M}$ website views per year

At BMC, research is always in progress.

Learn more biomedcentral.com/submissions 